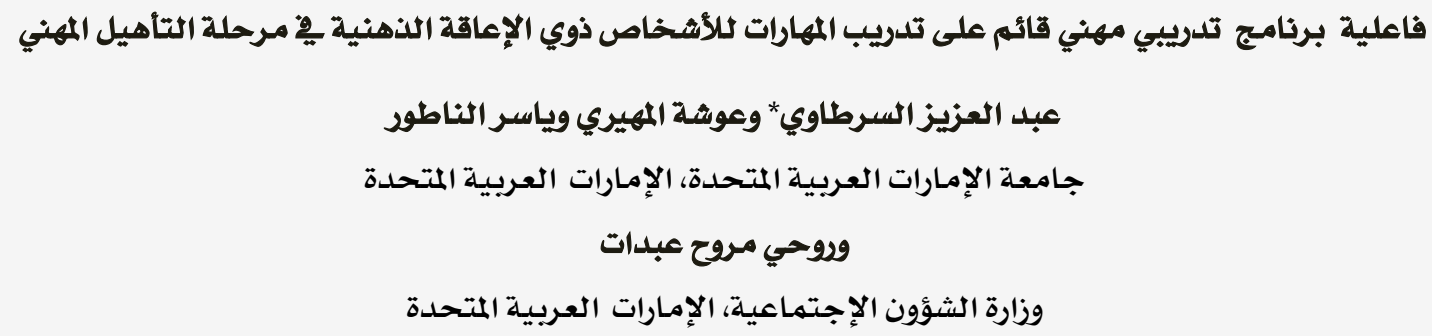

\title{
The Efficacy of Vocational Skills- Based Training Program for People with Intellectual Disabilities at the Stage of Vocational Rehabilitation
}

\author{
AbdelAziz Sartawi, ${ }^{*}$ Owaisha Al Muhairy, Yasser Al Natour \\ United Arab Emirates University, United Arab Emirates \\ \& Rawhi M. Obaidat \\ Ministry of Social Affairs, United Arab Emirates
}

\begin{abstract}
This study targeted investigating the efficacy of a vocational skill- based training program for people with intellectual disabilities. The program was set forth by the Department of Welfare and Rehabilitation of Persons with Disability, Ministry of Social Affairs (2009) at UAE. Subjects were 10 male individuals, age 15-20, with intellectual challenges who receive vocational training in Dubai Rehabilitation Center, UAE and who had an IQ score of 55-69 on Wechsler Adult Intelligence Scale (The Emirati Version). A control group was also recruited for the purpose of comparison $(n=10)$. The Vocational Skill Scale as introduced by the investigators and was conducted before then after 8 weeks of the initiation of the training program in the academic year 2012/2013. Results showed significant differences between the scores obtained by the experimental group pre and post training, whereas there were no significant differences in the control group. The investigators recommended generalizing the vocational training program across centers of intellectual disability rehabilitation and expanding the program to include personal and social skill in addition to implementing the kills in a real work setting.
\end{abstract}

Keywords: People with intellectual disabilities, vocational rehabilitation, United Arab Emirates.

*asartawi@ uaeu.ac.ae 


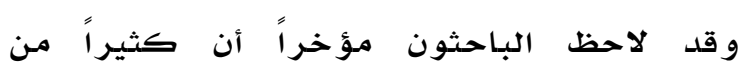

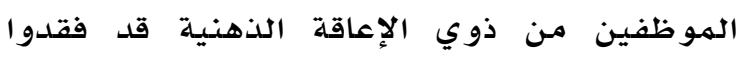

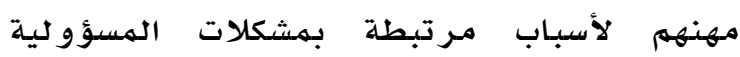
المهنية و مشكلات مهنية اجتماعية، أكثر منكونها مرتبطة بضعف في إنجاز مهام العمل الإنتاجية.

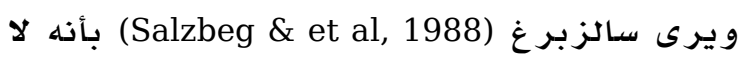

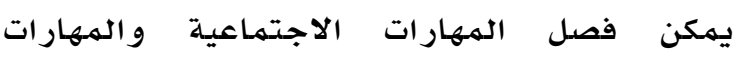

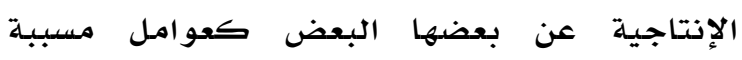

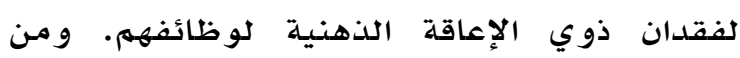

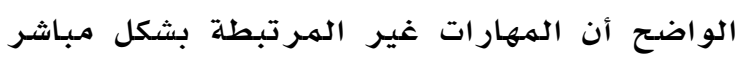

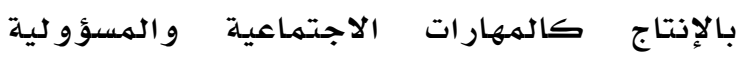
المهنية وهي عوامل ضرورية لتحقيق الكفاءة

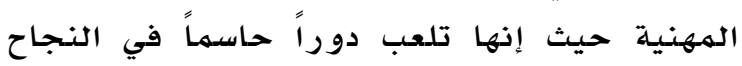
الوظيفي للعاملين منهه.

إن جزءاً كبيراً من العملية التدريبية في مرحلة

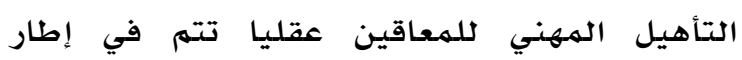

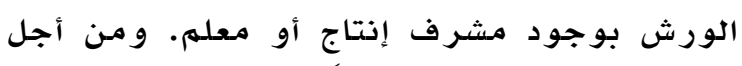

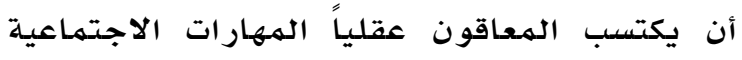

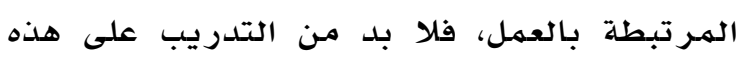

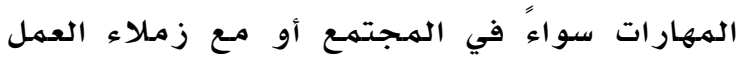

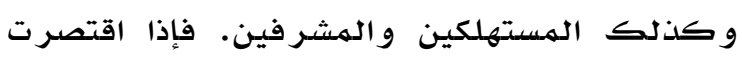

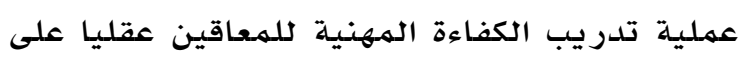

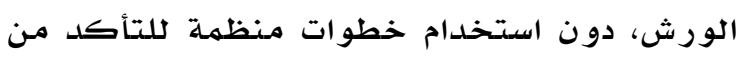

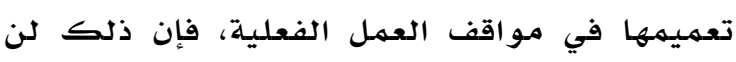
يكون كافياً للوصول بهم إلى مهارات وظيفية

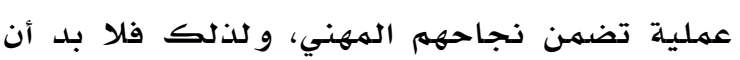

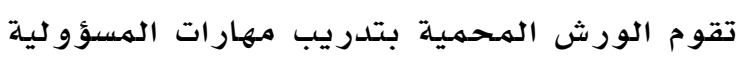

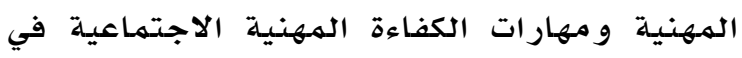

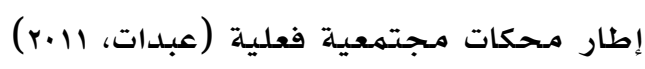
و تشير الدراسـات إلى أن تحسناً طفيفاً قد طرأ من الد الدئ

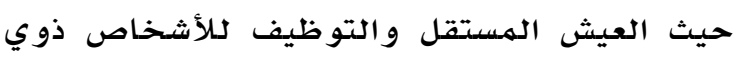
الإعاقة الذهنية في كل من الديثل الدول المتتقدمة

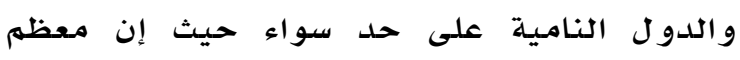

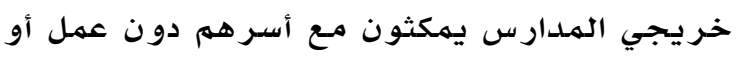

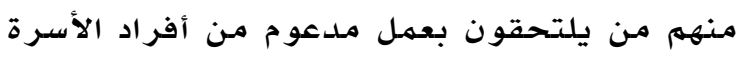
(Kniel, 1995; Luftig \& Dorothy, 2005) ذلك يعود إلى ضعف البرامـج التدريبية التي

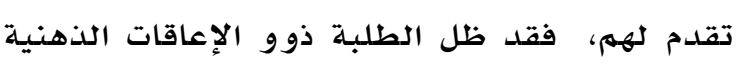

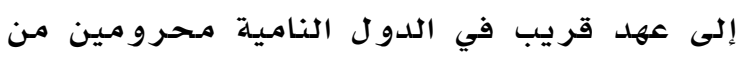

يشير العقد العربي لكلأشخاص ذوي الإعاقة (ع...ب-

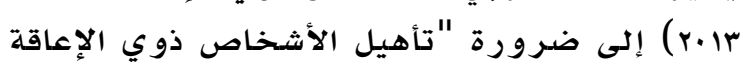

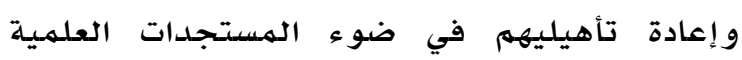

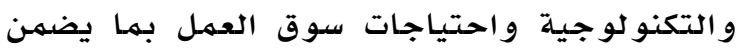

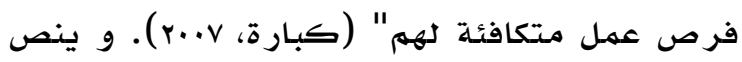

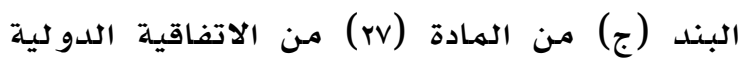

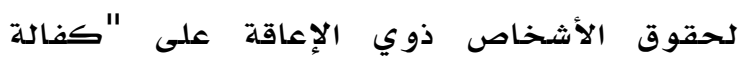

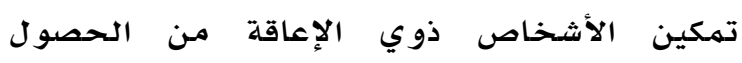

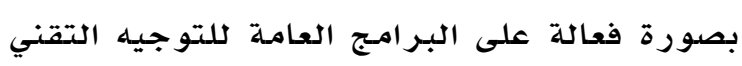

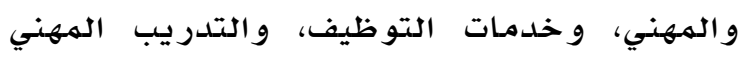

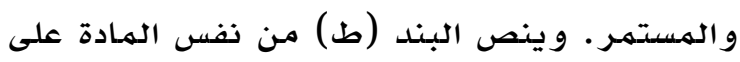

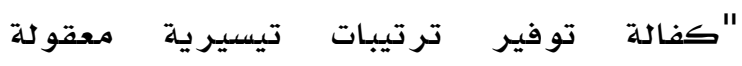

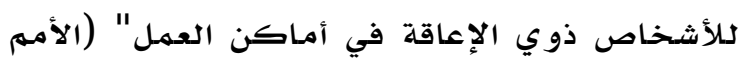

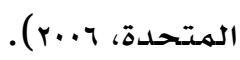

وقد تبنت الجمعية الأمريكية للإعاقات الذهنية

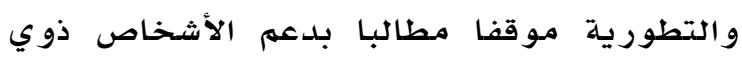

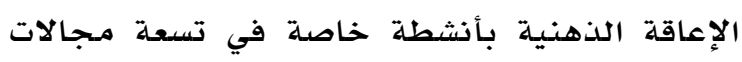

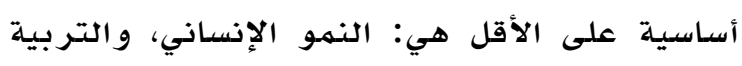

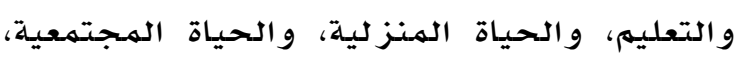

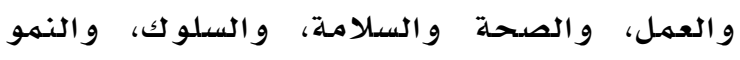

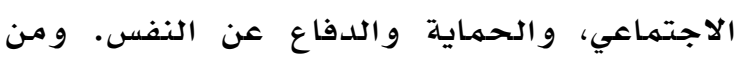

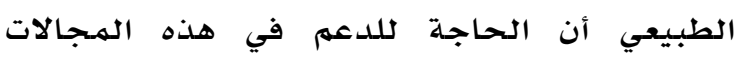
تصبيح أقل كلما انخفضت شلدة الإعاقة الذهنية

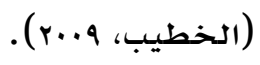

لقد أثبتت البحوث و التجارب العملية في التدريب

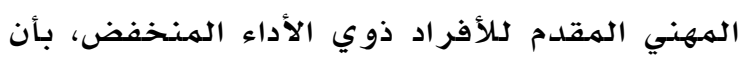

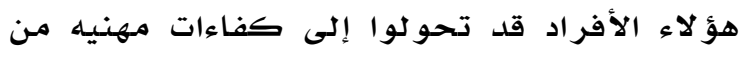

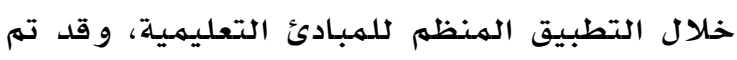

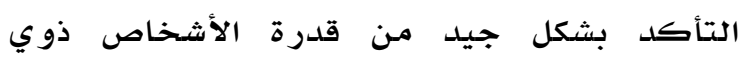

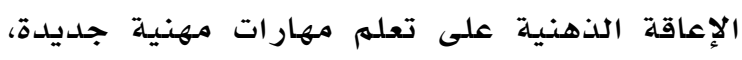

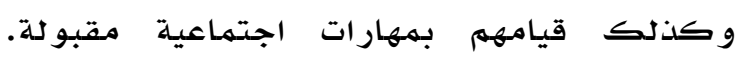

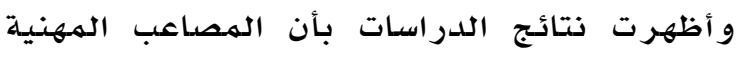

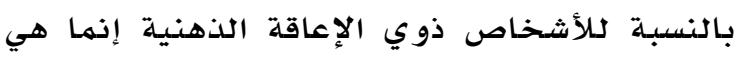

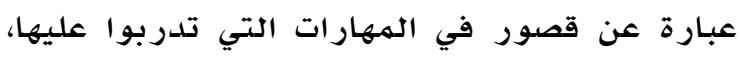
أكثر من كونها قصور في إمكانات الشخص ذو ذو

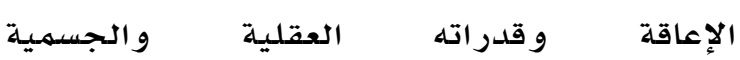
.(Markandeyan, 1992) 


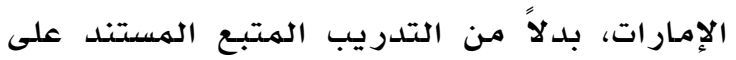

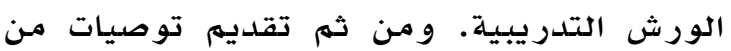

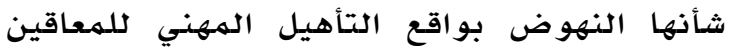
عقليا بدولة الإمارات العربية المتحدة.

(Murray \& Doren, لقد أجرى موري ودورين (2013 دراسة حول أثر منهاج (WAGES) الذي ودي يتضمن مهارات بيئة العمل في مرحلة التأهيل

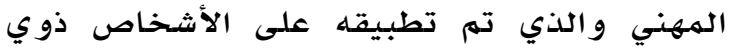

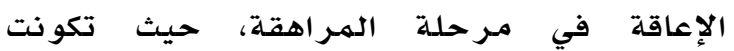
الدراسة من مجموعتين تجر يبية وضابطة، بحيث الإعالة

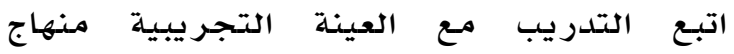

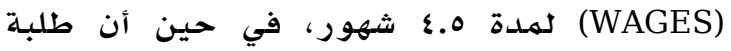

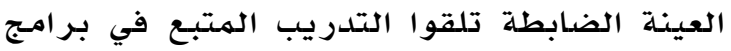

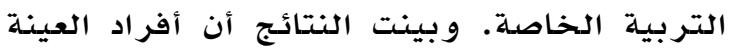

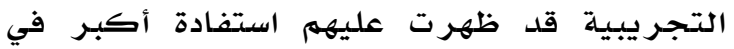

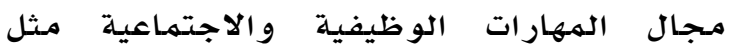

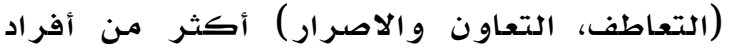

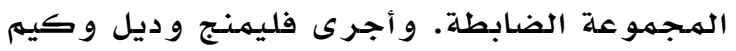
و ليهي (Fleming, Del, Kim \& Leahy, 2013) دراسة هدفت إلى فحص أبحاث التأهيل التي

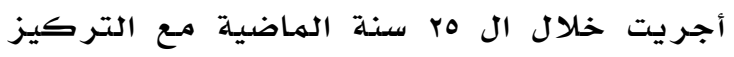

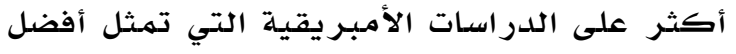

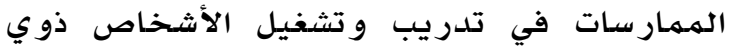

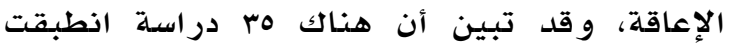

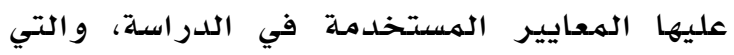

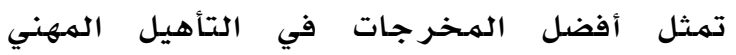

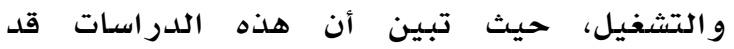
استخدمت تدريب الأشخاص ذاين ذوي الإعاقة الذي الذي الديات

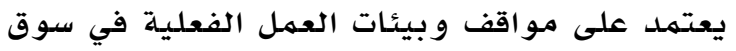

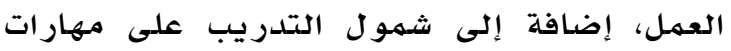
متنوعة اجتماعية وسلوكية عدا عن المهافئ المهارات

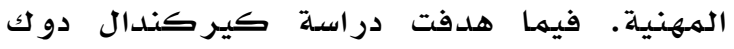
(Kirkendall; Doueck \& Saladino, وسالادينو (2009 إلى تقييم أثر برنامج تدريبي في الانتقال

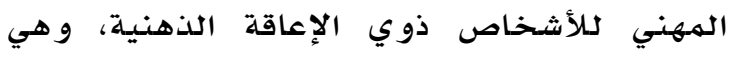

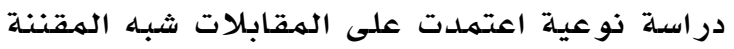

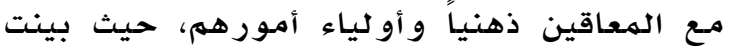

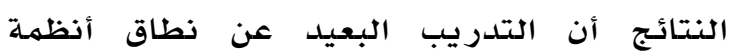

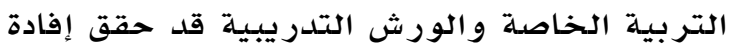

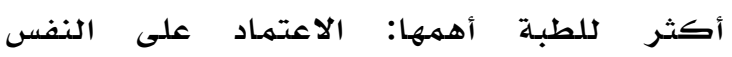

الالتحاق بالمدارس العادية. إضافة إلى أن نهط

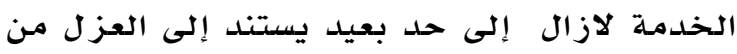

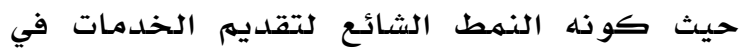
الدول النامية بما فيها الدول العربية. و في عالمنا العربي ليست عملية التأهيل بأفضل

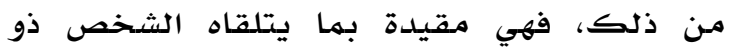

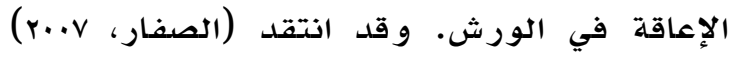

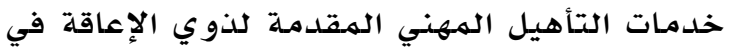

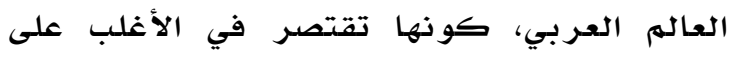

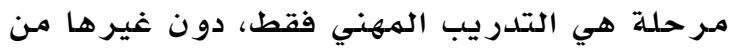

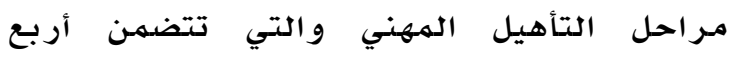

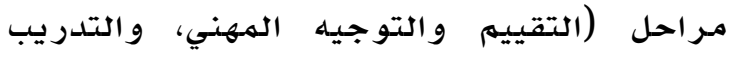

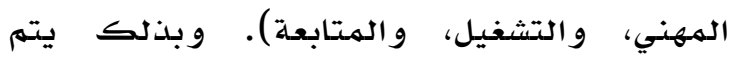

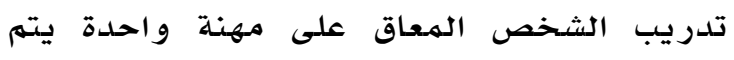
تحديدها دون إجراء دراسة واقعية لاحتياجات

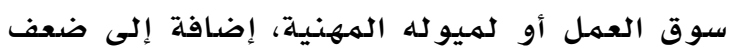

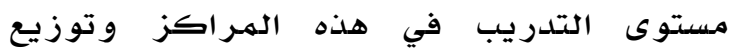
الأشخاص ذذوي الإعاقة على الأقسام المهنية

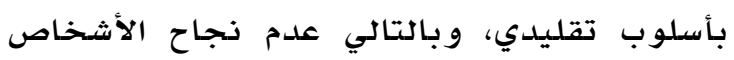

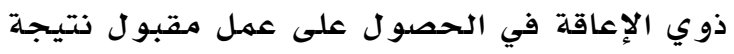

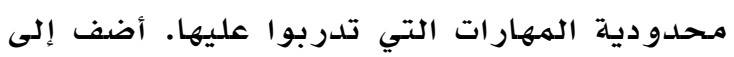

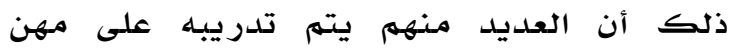

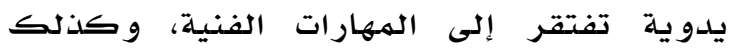

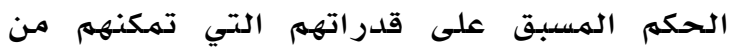

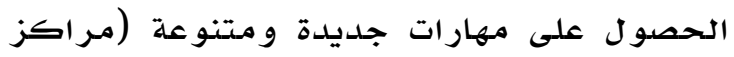

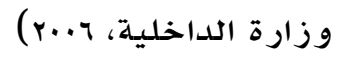
وبناء على جوانب القصور الواضح في برامج

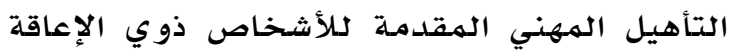

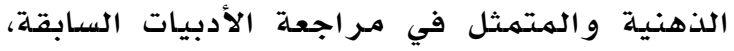

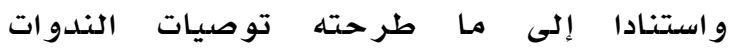

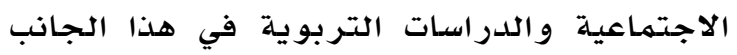

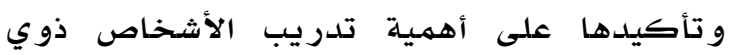
الإعاقة الذهنية بشكل غير تقليدي بحيث يشتهمل

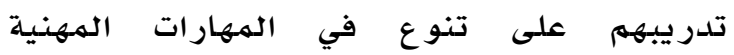

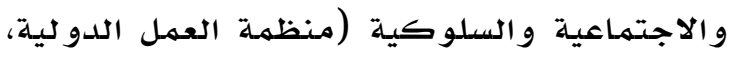

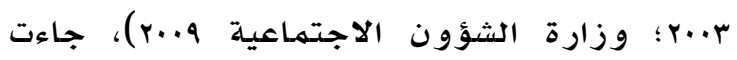

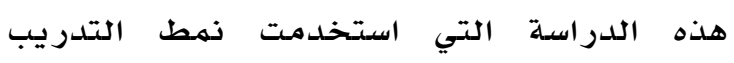

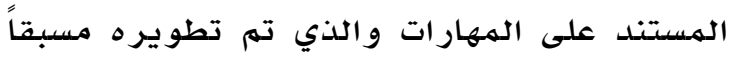

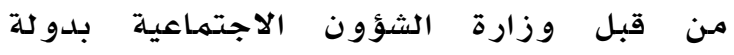


الصعوبات التي تواجه تدريب الأشخاص ذذوي الإعاقة في إغفال الجانب العملي في الههارات، إذ إذابل

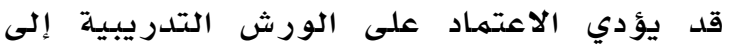
تدريب الشخص ذو الإعاقة بطرق غير علمية،

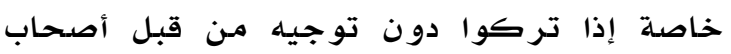

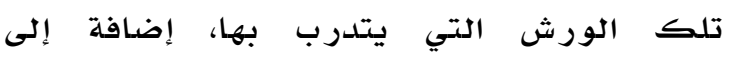

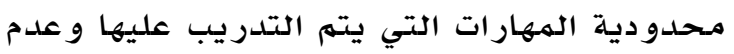

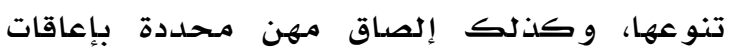
معينـة.

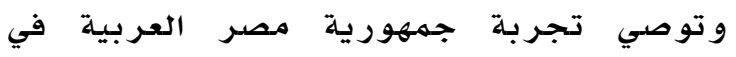
تدريب وتأهيل الأشخاص ذوي ذوي الإعاقة بضرورة بهورة دراسـة الههن التي يتتم التدريب الههني عليها في

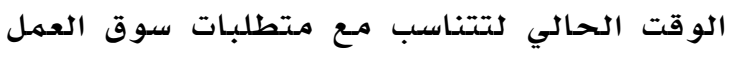

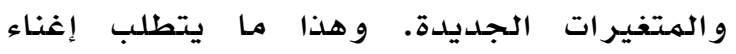

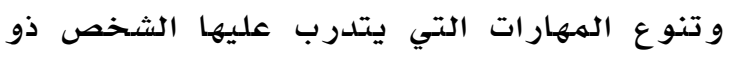

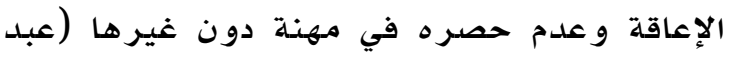

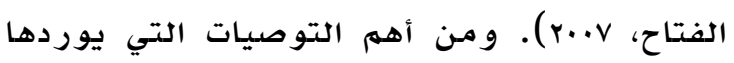

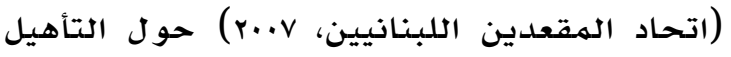
الههني للمعاقين ما يلي: مكافحة تدني الهمهارات عند الأشخاص ذوي الإعاقة، والذي يعتبر التحدي لإيدي الأول والذي في عدم تكافؤ المهن التي يتم

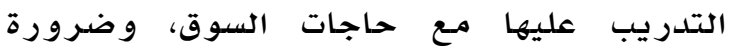

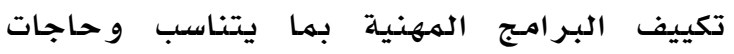

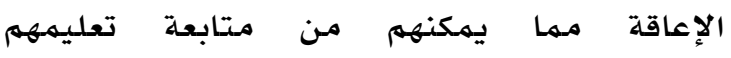
و تأهيلهم.

و قد هدفت دراسة الشمري (1994) إلى التعرف

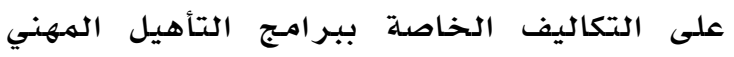

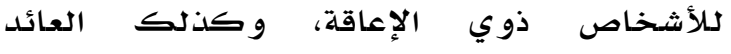

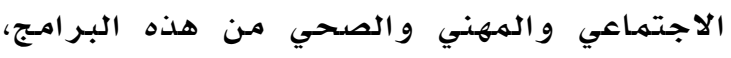

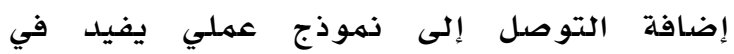

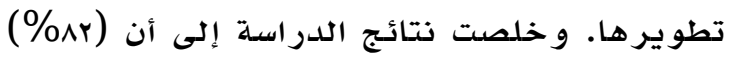

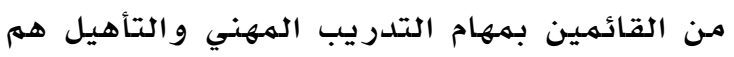

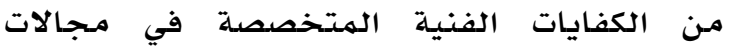

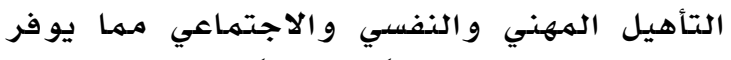
إلى حد كبير مناخاً إيجابياً لعملية التأهيل

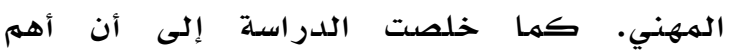
الهـالات التي يتدرب عليها المعاقون تنحصر في التهاء الكهرباء و النجارة والإلكتروونيات التي لا تلكفي سوق العمل الذي هو بحاجة إلى أكثر من هذه واءه

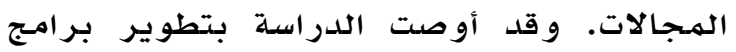

و اكتسـاب المفاهيم الحياتية والاجتماعية العامـة،

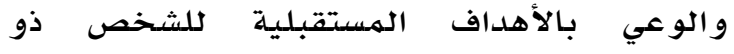
ألإعاقة، وهو ما أدى إلى تحسين تحقيق الأهداف

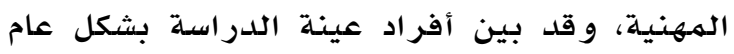
رضاههم عن البر نامج التدريبي.

و توصلت در اسـة بيلامي و آخرين Bellamy \& et)

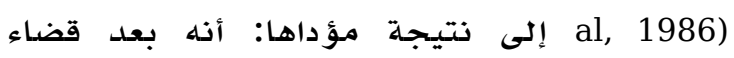
المتدرب فترة عامين أو أكثر في فودا الورش

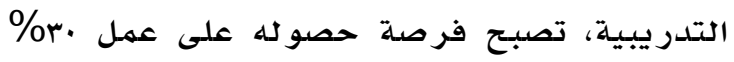

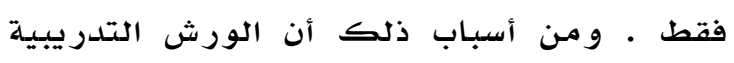
تركز على مهنـة واحدة دون الالتفات إلى

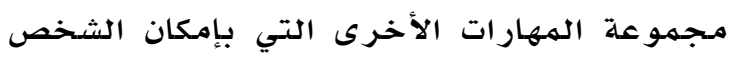
ذو الإعاقة القيام بها. فيما بحثث لدراس دراسلة إنج (Inge, 1988)

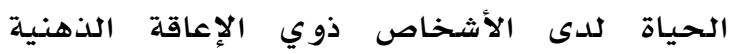

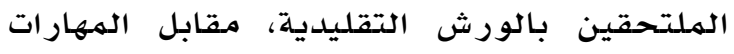
المتوفرة لدى الأشخاص ذانوي الإعاقة الذهنية

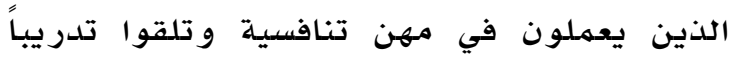

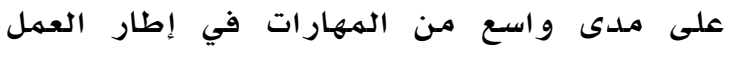

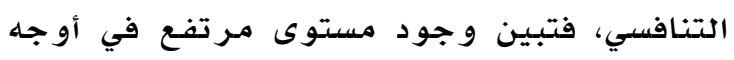

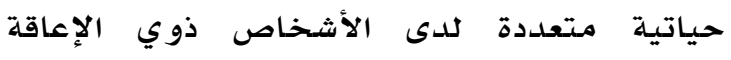
العاملين في التوظيف التنافسي الذين تدربوا

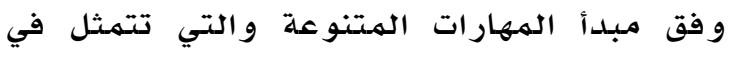
السلوك التكيفي، المشاركة الاجتهماعية، الهمارات

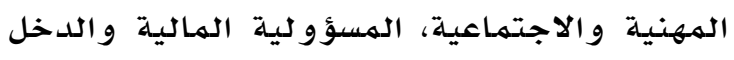

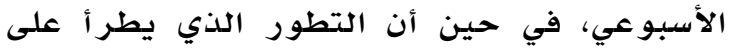

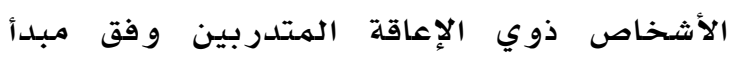
الورش يقتصر على مهارات تدريبية محدل مدودة، دون النظر إلى مهارات خارج نطاق المهنـة التي ملي يتدرب عليها والتي قد تسهمح بها قدر اته. وقد لخص (السقا، ع...r) أهم المعوقات التي تواجه تأهيل وتشغيل الأشخاص ذوي الإعاقة في عالمنا العربي بأن البرامج التأهيلية و التدريبية

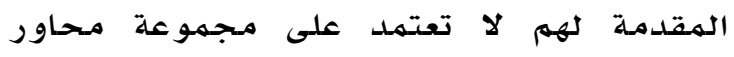

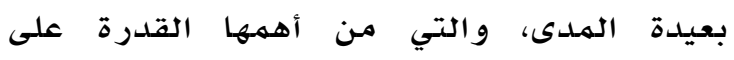

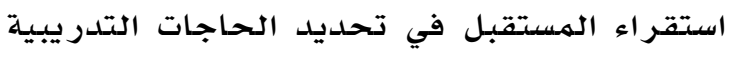
و الوظائف المتاحة، بل إنها تنحصر في في مجاءلات معينـة دون غيرها، إضافة إلى حاجـة المعاق أثناء

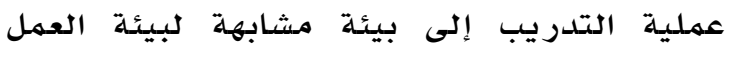

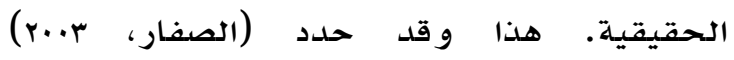




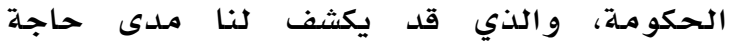

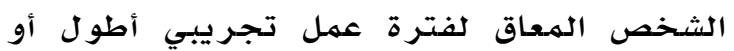

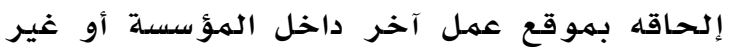
ذلك من الخدمات التي تعمل على تسهيل بقائه احهر في العمل وتدريبـه على مهارات تدريبية مناسبـة لبيئة العمل و ولقدراته، بحيث ت تكون المهارات متنوعة وغير محصورة في مهنة معينة.

وتوصي الندوة الاجتماعية حول مشكلات توظيف

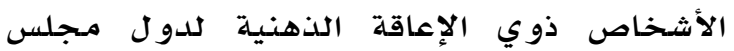

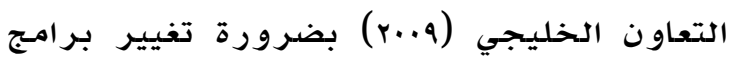

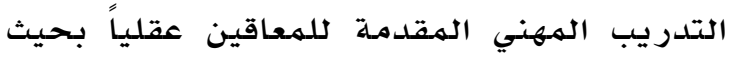
تتناسب مـع متطلبات سوق العمل، وتبني المـناهـج

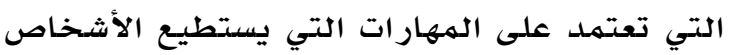

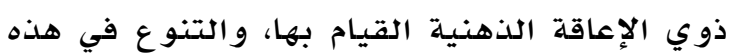

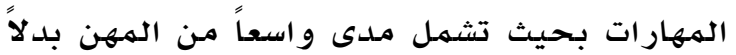

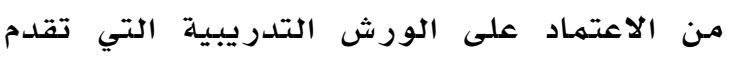

$$
\text { التدريب على مهنة و احدة. }
$$

\section{مشكلة الدراسة}

تعتبر عملية التأهيل الههني بالنسبة للأشخاص

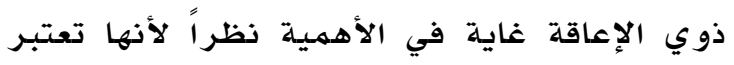

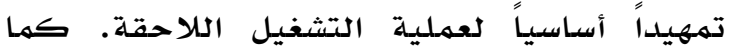
يعتبر نجاح عملية التشغيل انعكاساً لنجاح عملية

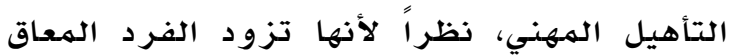

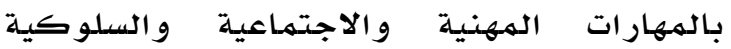

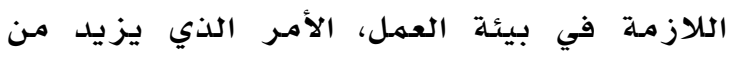

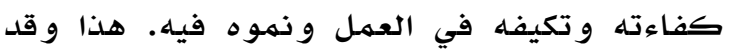
انتشرت في عالمنا العربي لسنوات طويلة ولهي عملية

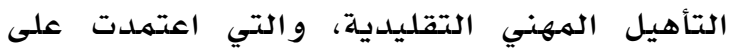

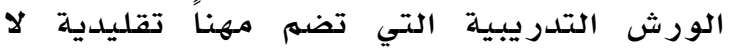

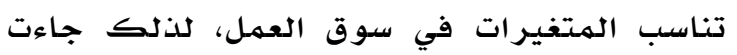
الدراسـة الحالية لقياس أثر عملية التأهيل الههني

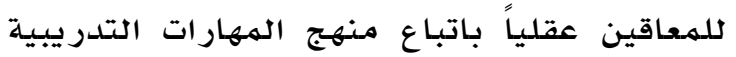

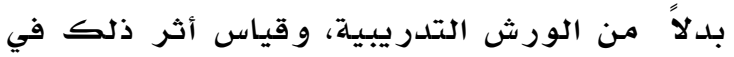
عملية التدريب. وبذلك تتحدد مشكلة الدراسة الدوريل في إجابتها على السؤال التالي: ولئ

ما مدى فاعلية برنامجج تدريبي مهني قائم على تدريب المهارات كلأشخاص ذوي الإعاقة العقلية في مرحلة التأهيل المهني؟
التأهيل الههني للهعاقين لتواكب التطورات العصرية في سوق العمل وإثر الك أولياء أمور

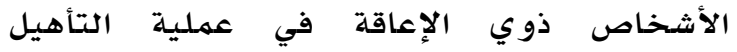
الاجتماعي و الهمهي. و يؤكد الشواهين (1919) أن خدمات التأهيل المهني لكلأشخاص ذوي الإعاقة في العالم العربي

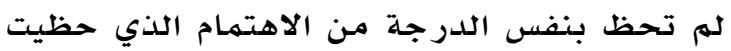

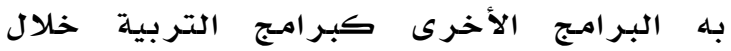

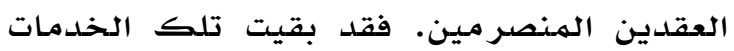

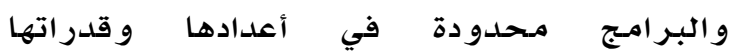
الاستيعابية و ونوعية الههن التي يتهم التدريب التهي

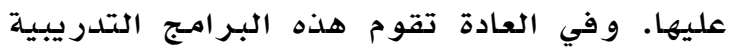
على التدريب على مهن تقليدية محلدو دة لا تساير

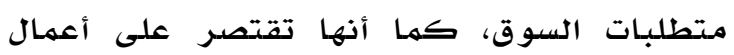
التنجيد والنجارة وصناعة الخيزران والخياطة

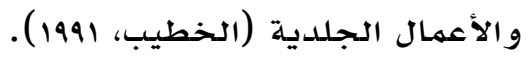

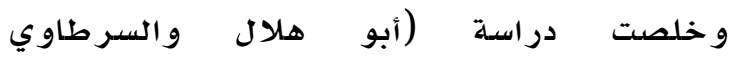

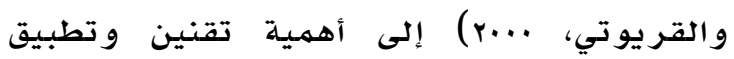

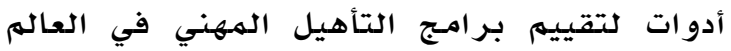

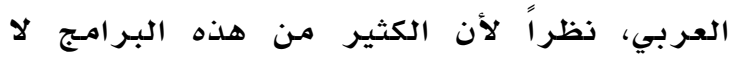

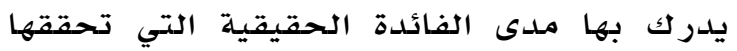
مثل هذه المقاييس كلأشخاص ذوي الإعاقة في

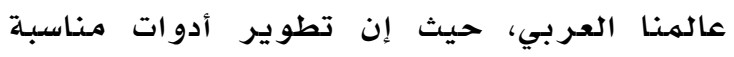

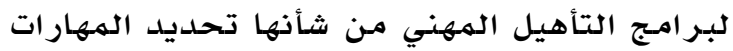

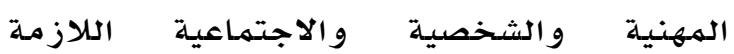
كلأشخاص ذوي الإعاقة قبل مرحلة والة التشغيل. و من أجل تطوير برامج التأهيل والتدريب

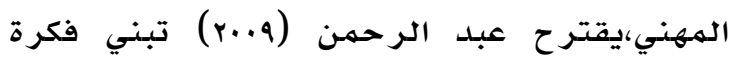
العمل من أجل الخبرة بحيث يتم توفير فرص عمليه من أجل تطوير

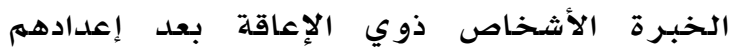

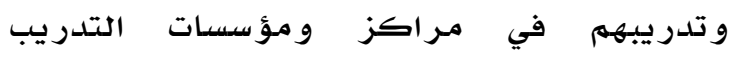

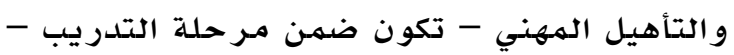

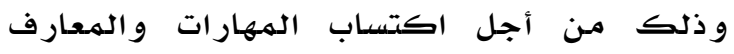

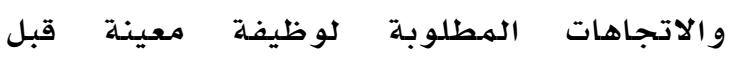
الالتحاق بها. و هذا الإجراء يقلل من فره صن فـل

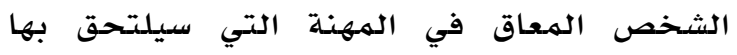

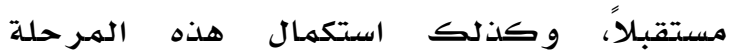
بهرحلة التشغيل التجريبي و العمل المدعوم من 
مصطلحات الدر اسة

الإعاقة الذهنية Intellectual disability: تعرّف الجمعية الأمريكية لإِعاقات الذهنية و النمائية (AAIDD) الإعاقة الذهنية على أنها:

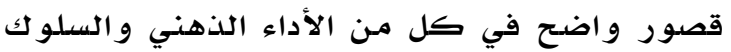

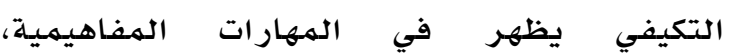
الاجتماعية والتكيفية العملية، وهيذ وهية الإعاقة تظهر قبل عمر 1 ا سنة - Schalock, Borthwick .Duffy \& Bradley, 2010)

Traditional Training برنامج التدريب التقليدي :Program

هو بر نامـج التدريب المهني للأشخاص ذذوي الإعاقة الذهنية الذي يستتند إلى الورش التدريبية

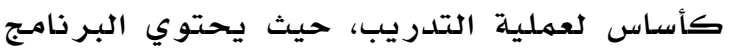

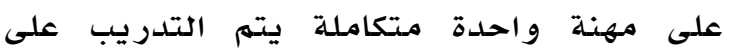

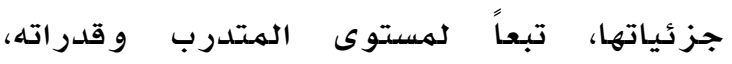

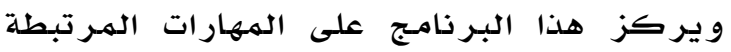
بالههنة الهوجودة في الورشلة دون الالتفات إلى إلى مهارات أخرى شخصية أو مهنية لها علاقة بههن

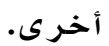

التأهيل المهني: Vocational Rehabilitation: تلك العمليات التي تهدف إلى مسداعدة الشخص

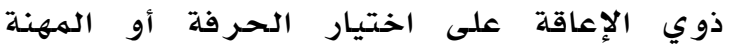

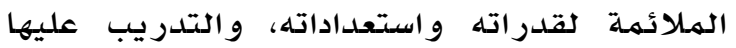

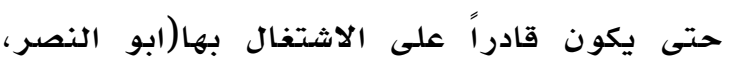
. (r...q

التدريب بالمهارات Task training:

ويعرف الباحثون التدريب بالههارات على أنه:

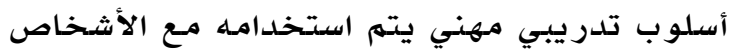

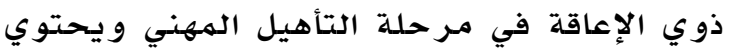

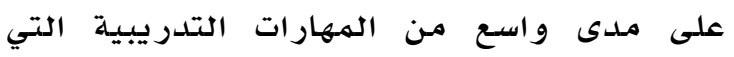
تتناسب مـع قدرات الشخص ذو الإعاقة و ميو له، مـا دام باستطاعته إتقان هذه الههارات، وذلك دوات دون حصر التدريب بههنة معينة دون غيرها. وبذاك

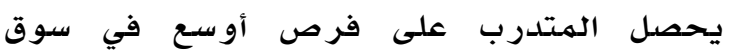
العمل، كونه يمتلك الكثير من الههارات في الهملي عدة مجالات تدر يبية.
فرضيات الدراسة

الفرضية الصفرية الأولى: لا توجد فروق ذات

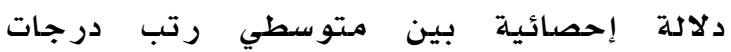

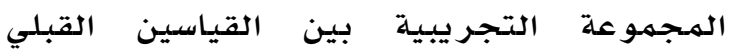
و البعدي في المهار ات المهنيـة والسلو كك الهـهني. الفرضية الصفرية الثانية: لا توجد فروق ذات

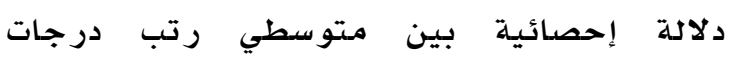
الهجموعة الضابطة بين القياسين القبلي و البعدي دئي في المهارات المهنية و السلو ك المهني. الفرضية الصفرية الثالثة: لا توجد فروق ذات

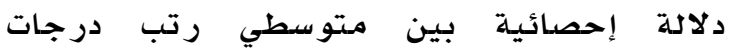
المجموعتين التجريبية والضـابطة في المهارات

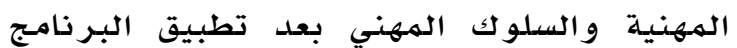
التدر يبي.

أهداف الدراسة

سعت هذه الدراسة إلى تحقيق الأهداف التالية: التعرف على فاعلية التدريب المهني وفق مبدأ المهارات في تطوير المههارات

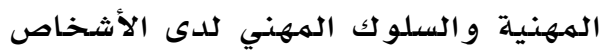
ذوي الإعاقة الذهنية البسيطة.

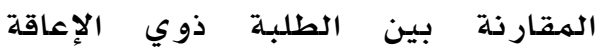
الذهنية الذين يتلقون التدريب الهمهني في الورش التدريبية، والطلبية الذين يتلقون التدريب المهني وفورنق منهاج

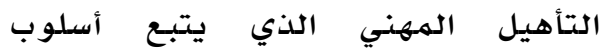
التدريب القائم على المهار ات. الهئي

حدود الدراسة تتحدد الدراسـة بالفترة الزمنية التي أجريت

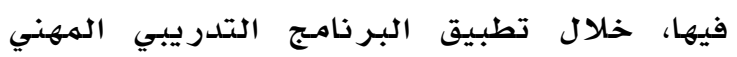

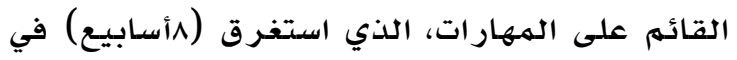

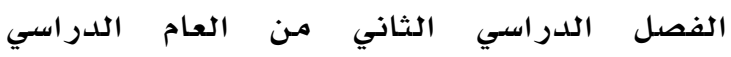

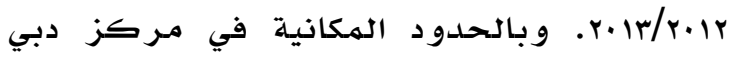

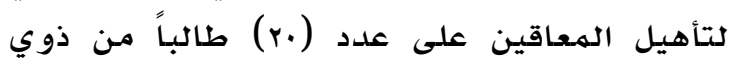
الإعاقة الذهنية البسيطة. 
أخلاقيــات العهـل و العنايـــة الشخصــية) دون

التركيز على مهنة محددة دون غيرها.

\section{الطريقة والإجر اءات}

\section{منهجية الدراسة}

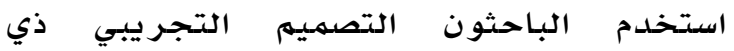

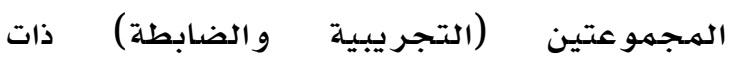

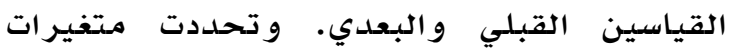
الدراسة على النحو التالي:

أ- المتغير المستقل: منهاج التأهيل المهني لذوي الإعاقة الذهنية

ب- المتغير التابع: المهارات التدريبية المهنية ج- اعتمدت الدر اسلة على الأدوات التالية:

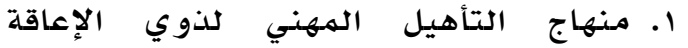
الذهنية (وزارة الشؤون الاجتماعية، و...r) r. استبيان المهارات المهنية من إعداد

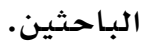

\section{مجتمع الدراسة وعينتها}

تكونت عينة الدراسة من (.r) طالباً من ذوي

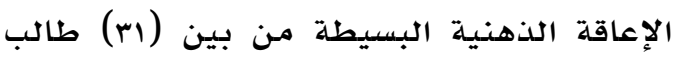

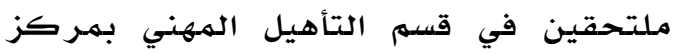
دبي لتأهيل المعاقين، و الذين تتراوح قدر اتهم الهين

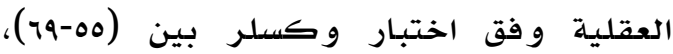

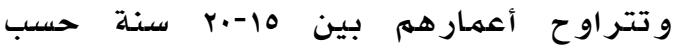

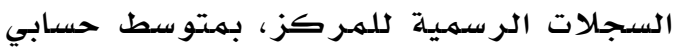

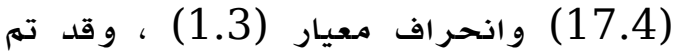
اختيار أفراد عينة الدراسة بطريقة عشوائية.

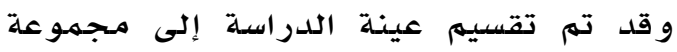
تجريبية (.1) طلبة، و مجمو عة ضابطة (1.) طلبة، بحيث تم مر اعاة أن تكون عينة الدر اسة التها متجانسة من حيث العهر والقدرات العقلية، و ذلك بعد تطبيق الاختبارات القدرات العقلية و الاطلاع على ملفاتهم النفسية و الاجتماعية.

$$
\text { أدوات الدراسة }
$$

أولاً: منهاج التاهيل المهني لذوي الإعاقة

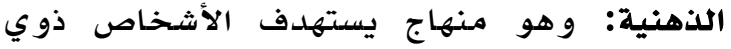

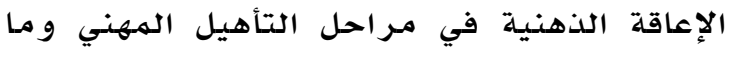

التشغيل Job Placement

هو الهدف الرئيسي والنهائي الذي تسعى إليه التربية الخاصة و برامجج التأهيل الهمني حيث أنها يساعد الفرد المعاق على الكسب الكريهم مقابل

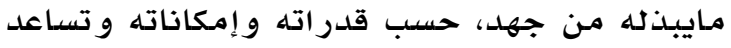
عملية التشغيل يساعد الفرد المعاق على الاندماج إنداج

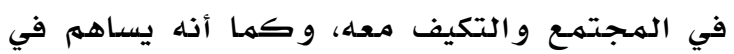

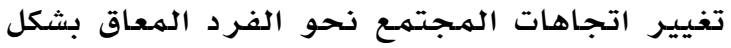

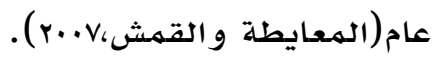
المدرب المهني Vocational Instructor: الشخص المسؤول عن مشاغل التدريب المهني أو الو

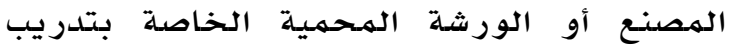

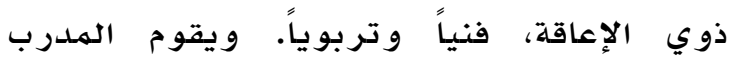

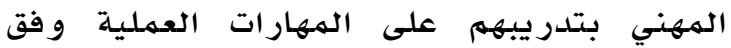

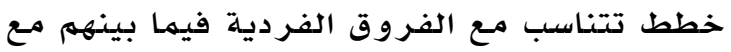

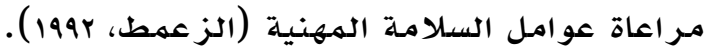

الأشخاص ذوي الإعاقة الذهنية البسيطة: هم الاشخاص الذين لديهم القدرات والامكانيات

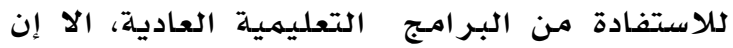
عملية تقدمهم تكون بطيئة مقارنة بالعاديين.

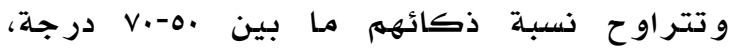

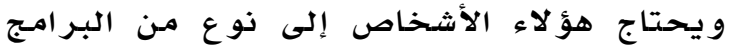

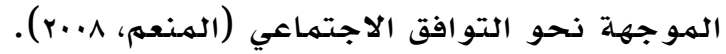

\section{منهاج التاهيل المهني كلأثـخـاص ذوي الإعاقـة}

الذهنية Curriculum: منهاج التايل منهج من إعـداد إدارة رعايـة وتأهيـل المعـاقين

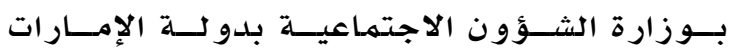

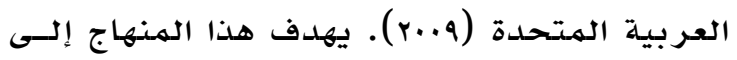

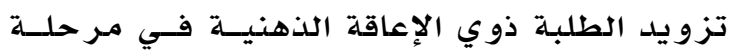

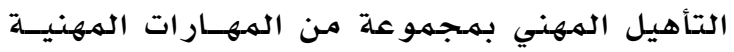

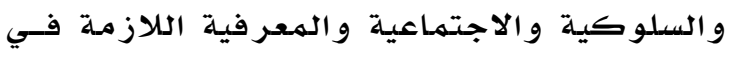

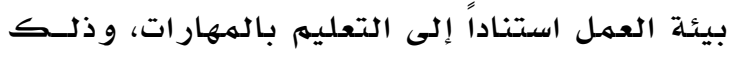
بغض النظر عن المهن التي من المتوقع أن يعمل

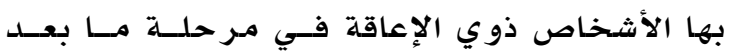

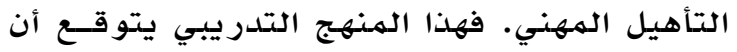

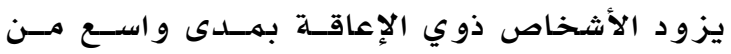

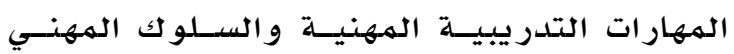

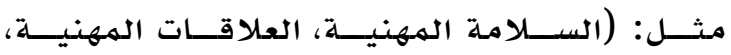




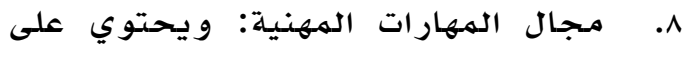

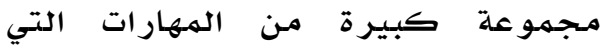
تناسب الطالب، من قص وقطع و وتغليف و تصنيف وقياس، حيث يحتوي مهارات مناسبة لكل من الذكور و الإناث.

مجال التدبير المنز لي: ويحتوي مهارات

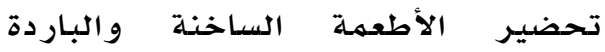
و المشروبات، و إدارة الهنز ل و استخدهام أدوات التتظيف، وتم استثناء هذا المهجال

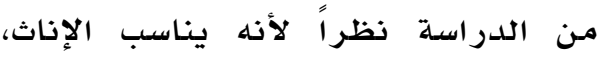
حيث تم استثناؤه من الدر اسلة. •l. الهمال الهعرفي: ويحتوي على مجمهوعة من المهار اتهات والحسابية التي تفيد الطالب في بيئة

العمل، حيث تم استثناؤه من الدر اسلة. وقد تم عرض هذا المنهاج في مرحلة إعداده

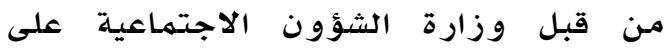

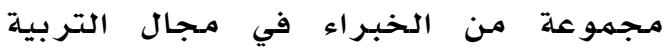

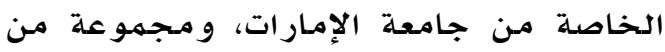

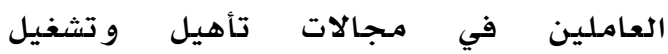

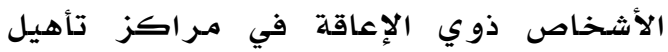
ذوي الإعاقة في الدولة، إضدافة إلى خبير

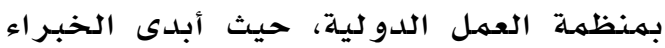

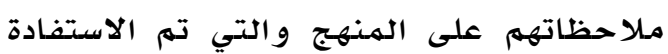
منها و تعديل بعض البنود بناء عليها. ثانياً: استبيان المهارات المهنية: تم تطوير أداة

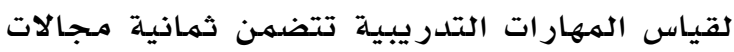
من المجالات العشرة الواردة في منهاج التأهيل

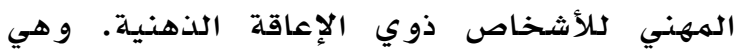

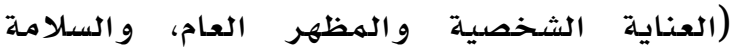

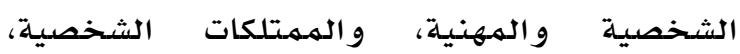

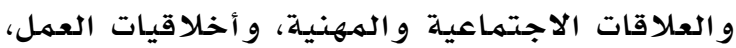

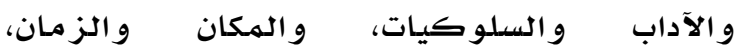

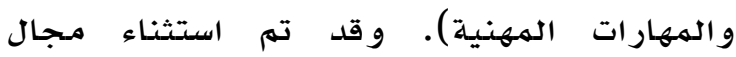

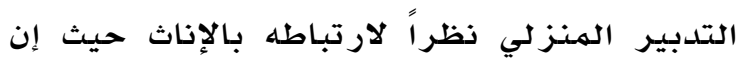

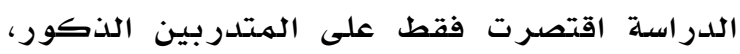
وكذلك استثناء مجال المهارات المعرفية حيث إن تركيز هذه الدراسة اقتصر على المهارات

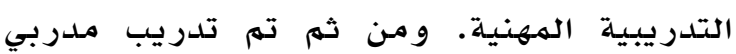

قبل المهني، أعدته إدارة رعاية و تأهيل الهعاقين

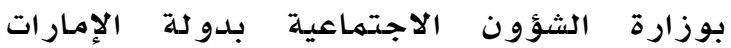

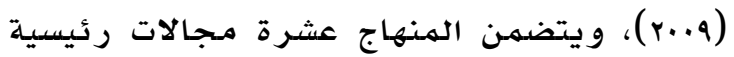

1. مجال العناية الشخصية والمظهر العام: و يتضمن مهارات أسـاسية للطالب تسـاعده على الاعتمـاد على ذاته في بيئة العمل،

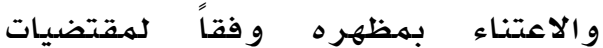
المهنة.

r. مبال السلامة الشخصية والمهنية: و يهدف إلى تمكين الطالب ذو الإعاقة من

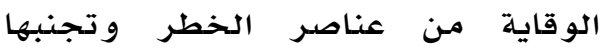
و التوعية بها، والقدرة على التصرف فند وقوع المـخاطر .

r. مجال الهمتلكات الشخصية: وتحتوي على مهارات تمكن الطالب من الحفاظ

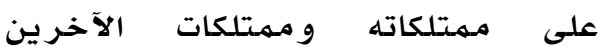
و ممتلكات العمل من أجهزة و وأدوات وو صيانتها عند اللزوم.

ع. مجال العلاقات الاجتماعية والمهنية:

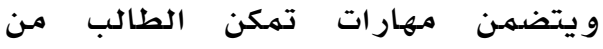
التواصل مـع الآخرين مـن زملاء ورؤساء

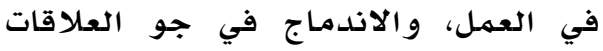
المهنية و التكيف مـع العاملين في بيئة

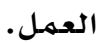

0. مجال أخلاقيات العهل: يزود هذا الهجال

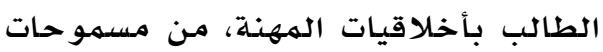
و محظورات، و أنظمة و تعليمات، و نظافة و وتر تيب.

1. مجال الآداب والسلوكيات: يحتوي هذا

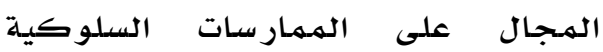
المطلوبة في بيئة العمل وقت الطعام

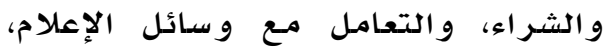
و أهمية الوقت في حياته الههنية. V. مجال المكان والزمان: ويتضمن التعرف

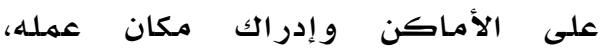
و أوقات العمل والاستر احلة و والإجازات و الهناسبات، و غير هـا. 


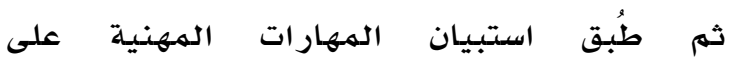

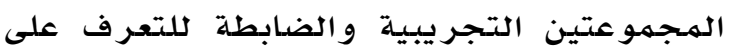

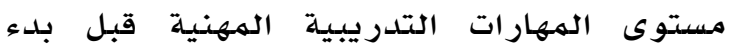

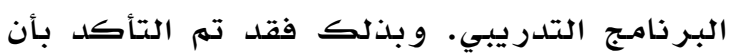

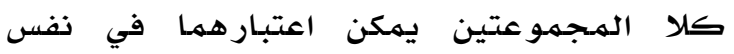

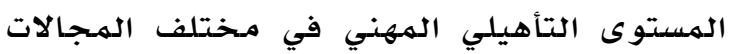

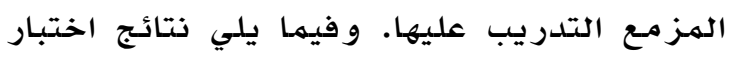
مان و يتني التي تؤكد ذلك الكئ ويمثل الجدول ا المهالات الثمانية التي تم

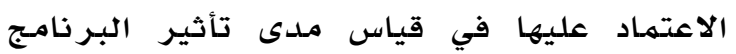
التدر يبي عليها.

و يـاحظ من الجسـدول عـدم وجــود فــروق دالسـة

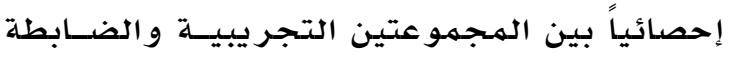

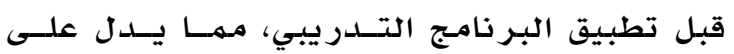

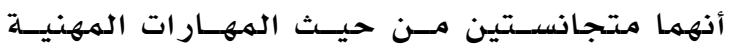

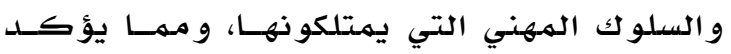

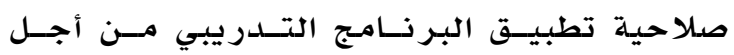

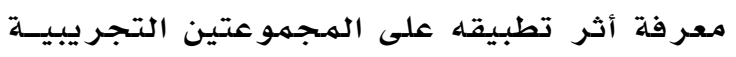
و الضابطة.

قام الباحثون باختيار منهاج التأهيل الههني كلأشخاص ذوي الإعاقة الذهنية مـن إعداد وزارة

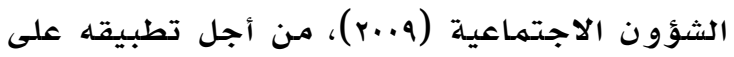

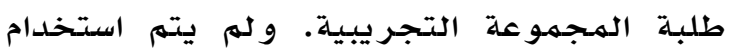

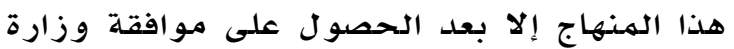
الشؤون الاجتماعية التي أوعزت لإدارة مركز مركز

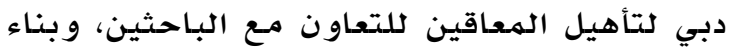
عليه؛ تواصل الباحثون مـع فريق العمل المعين

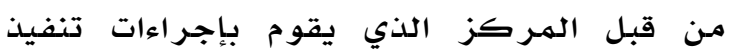

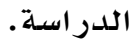

التأهيل الههني على كيفية تعبئة الاستمارة

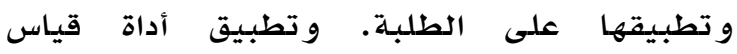

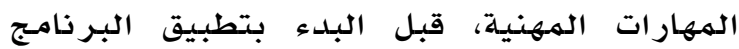
التدريبي على المجمووعتين التجر يبية والضـابطة. احتوى الاستبيان على (·ء) فقرة، حيث تم تضمين كل مـجال مـن المـالات الثمانية بخمس الثمس

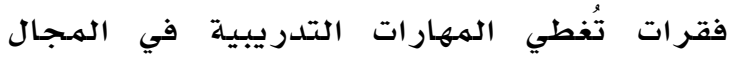
نفسـه، وتمت صياغة هذه الفقرات بشكل إيجابي يعبّر عن إتقان الطالب للهمهارة واكتسابه لها.

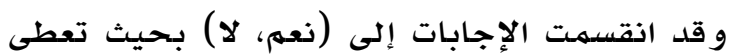

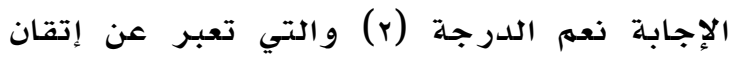

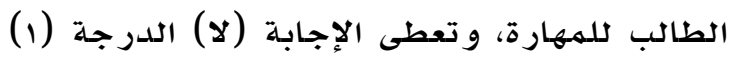
و التي تعبر عن عدم إتقان الطالب للهمهارة، وبذلك تتراوح الدرجات التي يحصل عليها الطالب في كل مـجال من المجالات بين (1-.1). و مـن أجل التحقق من صدق وثبات الاستبيان، تم

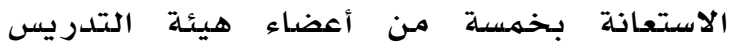

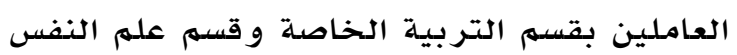

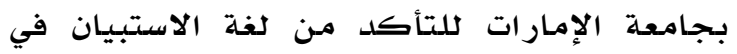

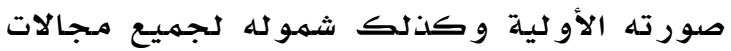

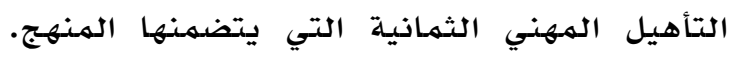

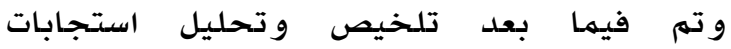
المحكمين و تعديل بعض البينود الخاصدة بأداة الدراسـة بمقتضى آرائهم في حالة إجماع ثلاثلة

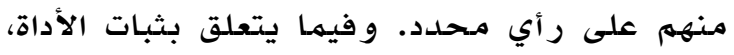

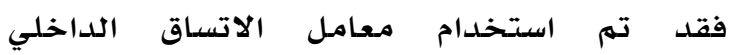

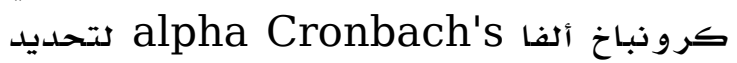
ثباتها و الذي بلـغ (يv.خ. ).

\section{إجر اءات الدر اسة}

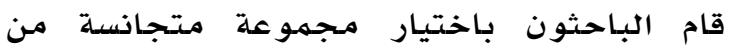

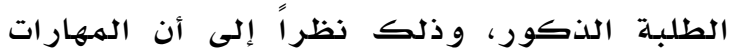

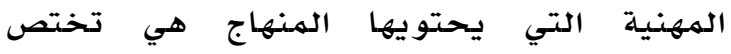

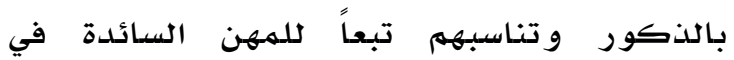

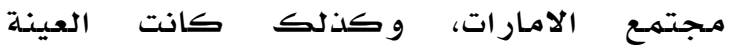

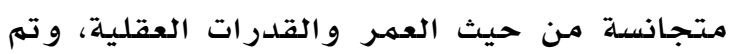

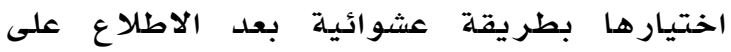
الملفات النفسية والاجتماعية الخاصدة بـالطلبة،

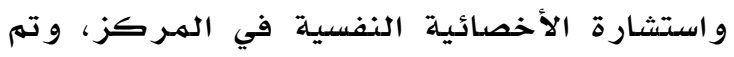
تقسيه العينة إلى مجموعتين تجريبية وضابطة. 
جدول

نتائج اختبار مان ويتني لعدم وجود فروق بين المجموعتين التجريبية والضابطة قبل تطبيق البرنامج التدريبي

\begin{tabular}{|c|c|c|c|c|c|c|c|c|c|c|}
\hline \multirow{2}{*}{ الدلالة } & \multirow{2}{*}{ Z } & \multirow{2}{*}{ W } & \multirow{2}{*}{ U } & \multicolumn{2}{|c|}{ مجموع الرتب } & \multicolumn{2}{|c|}{ متوسط الرتب } & \multicolumn{2}{|c|}{ المتوسط } & \multirow[t]{2}{*}{ المجال } \\
\hline & & & & الضابطة & التجريبية & الضابطة & التجريبية & الضابطة & التجريبية & \\
\hline $1 \ldots$ & $\ldots$ & 1.0 & 0. & 1.0 & 1.0 & 1.00 & 1.00 & $\varepsilon \ldots$ & $\varepsilon \ldots$ & العناية الشخصية \\
\hline$\because 1 \wedge 9$ & אוזיו & $\wedge \wedge .0$ & o & $1 Y 1.0$ & $\wedge \wedge .0$ & 14.10 & ^.^० & $\varepsilon . \varepsilon$. & 「.^. & السلامة المهنية \\
\hline •.人ז乏 & $\cdot r \cdot q$ & $1 \cdot r .0$ & $\varepsilon V .0$ & $1 . v .0$ & $1 \cdot$ T.0 & $1 . .20$ & $1 . .10$ & $\varepsilon .7$ & $\varepsilon .0$. & الممتلكات \\
\hline & & & & & & & & & & الشخصية \\
\hline $1 \ldots$ & $\cdots$ & 1.0 & 0. & 1.0 & 1.0 & 1.00 & 1.00 & r.А. & r.A. & العلاقات المهنية \\
\hline$\because \vee \wedge T$ & . TVY & 1.1 .0 & $\leqslant 7.0$ & 1.1 .0 & $1 \cdot 1.0$ & $1 . .10$ & $1 . .10$ & r.r. & r.o. & أخلاقيات العمل \\
\hline $.7 \wedge \varepsilon$ & $\cdot . \varepsilon \cdot 7$ & $1 \ldots$ & $\leqslant 0$ & $1 \ldots$ & 11. & 1. & 11 & ะ.7. & $\varepsilon . \wedge$. & الآداب \\
\hline$\cdot \wedge \leq \Gamma$ & $.19 V$ & $1 \cdot r .0$ & $\leqslant V .0$ & $1 \cdot v .0$ & 1. T.0 & $1 . .10$ & $1 . .50$ & r.V. & T.V. & المكان والزمان \\
\hline$\cdot . \wedge \cdot 1$ & .ror & $1 \cdot r$ & $\varepsilon V$ & $1 \cdot 1$ & $1 \cdot r$ & $1 \cdot .1$ & $1 . r$ & $\varepsilon .7$. & $\varepsilon .0$. & المهارات المهنية \\
\hline
\end{tabular}

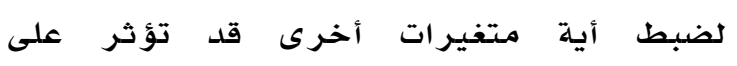
البر نامـج التدريبي.

و بعد انتهاء فترة تطبيق البرنامـج التدريبي الههني، قام الباحثون بتطبيق استبيان المهارات

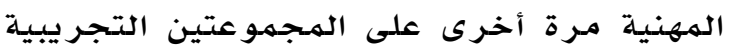

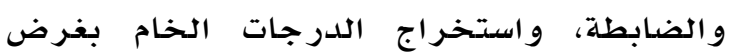
قياس الفروق الإحصدائية بين القياسين القبلي

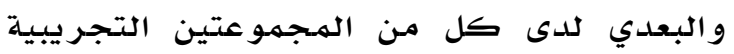

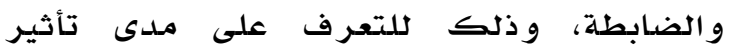

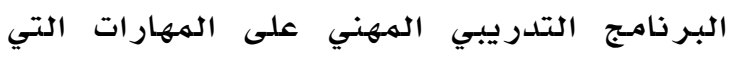
يكتسبونها في المجالات التدرريبية الثمانية.

المعالجات الإحصائية

تم استخدام الاختبار ات التالية: اختبار مان ويتني Mann-Whitney، و واختبار و يلكوكسون Wilcoxon، و وقيمة (Z).

\section{مناقشة النتائج}

نتائج الفرضية الصفرية الأولى: لا توجد فروق ذات دلالة إحصائية بين متوسطي رتب درجات

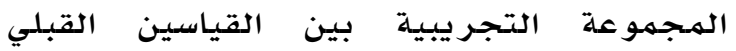
و البعدي في الههارات الههنية و السلو ك الههني. يتضح من نتائج جدول (r) وجود فروق اتو ذات

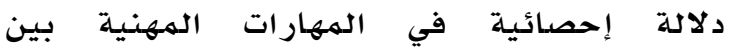
متوسطي رتب درجات الهـجموعة التجريبية قبل

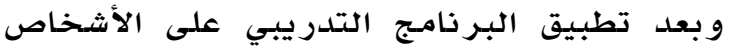

شارك في تنفيذ البرنامهج التدريبي كل من:

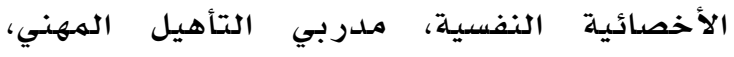
الأخصائية الاجتماعية، المنسقة التربوية، و وتم الهم

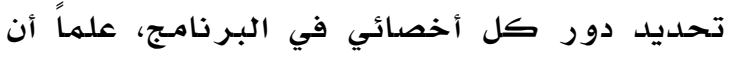
الأخصائيين و مدربي التأهيل الههني همر من ذوي الخبرة و الكفاءة في الهر كز ، وسبق لهمه تطبيق

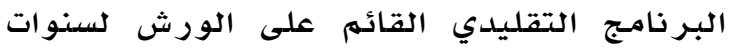

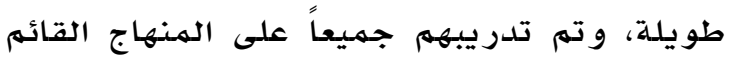
على الهـارات مـن قبل الوزارة قبل تطبيقه. و بعد الانتهاء من الإجراءات التفعيلية لتنفيذ

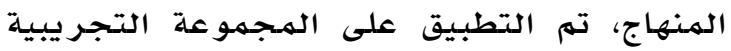
لمدة (^) أسابيع بواقع خمسة اليام في الأسبوع. وخلال فترة التطبيق هذه، عُقدات اجتماعات

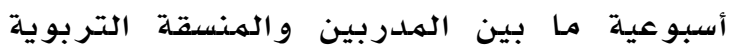

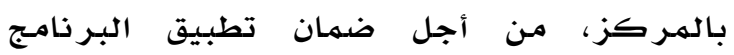
التدريبي بشكل جيد، و والتواصل مـع الباحثين لتلافي أية مشكلات، و إعطاء تغذية رلية راجعـة مناسبـة للمعلمات و الأخصائيين في التطبيق. اتبع الهدربون الههنيون مع العينة التجريبية نفس طريقة التدريب الهتبعتة في البرنامـج

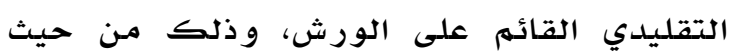
اتباع نموذج الخطة التدريبية الفردية لكل طالب الب لوريل

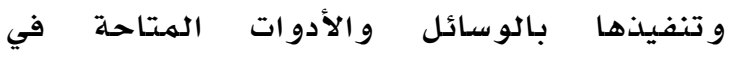

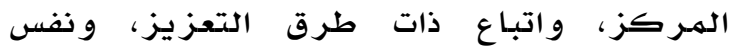

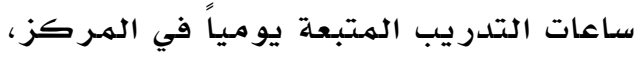


المتبعة في منهاج التأهيل الهمهني تعد مهارات

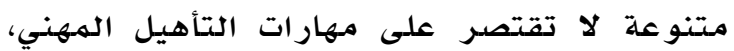

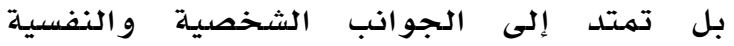
و التواصلية التي يعايشها الموظف في بيئة العمل. فالمتدرب لا يتوقع أن يصاب بالملل من جراء التركيز على مهارات معينة في مهنـة محلددة

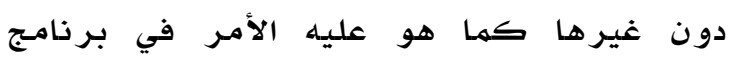
التأهيل المهني التقليدي. و تتفق هذه النتيجلة مـع

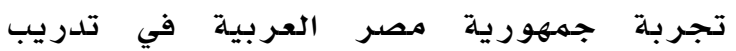
و تأهيل الأشخاص ذوي الإعاقة، التي توصلت
ذوي الإعاقة الذهنية البسيطة، وذلك لصالح

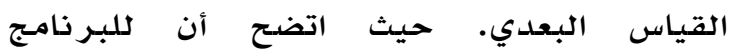

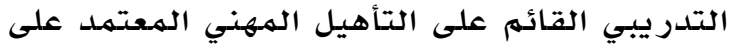

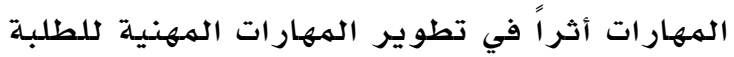
في المـجالات الثمانية الواردة في منهاج التأهيل

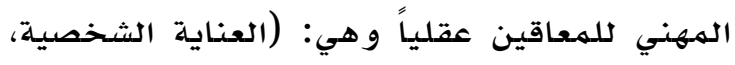

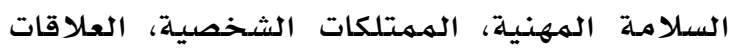

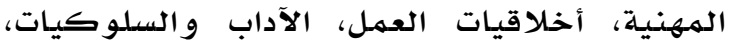

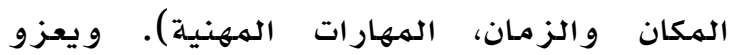
الباحثون السبب في ذلك إلى أن الهـان الهرارات

جدول r

نتائج اختبار ويلكوكسون ودلالته الإحصائية للفروق بين متوسطي رتب درجات المجموعة التجريبية بين القياسين القبلي والبعدي على استبيان

\begin{tabular}{|c|c|c|c|c|c|c|}
\hline مستوى الدلالة & قيمة Z & مجموع الرتب & متوسط الرتب & العدد العد & الرتب & أبعاد استبيان \\
\hline \multirow[t]{4}{*}{$* \ldots 11$} & $r .000$ & r & «.०. & $\wedge$ & العالبة & العناية الثخصية \\
\hline & & $\cdots$ & $\cdots$ & . & الموجبة & \\
\hline & & & & r & التساوي & \\
\hline & & & & 1. & المجموع & \\
\hline \multirow[t]{4}{*}{$* \ldots \wedge$} & T.TVT & $\leq 0$ & $0 . .$. & 9 & السالبة & السلامة المهنية \\
\hline & & $\cdots$ & $\cdots$ & . & الموجبة & \\
\hline & & & & 1 & التساوي & \\
\hline & & & & 1. & المجموع & \\
\hline \multirow[t]{4}{*}{$* \ldots 11$} & r.orq & rq & $\leq .0$. & $\wedge$ & السالبة & \\
\hline & & $\cdots$ & $\cdots$ & . & الموجبة & الممتلكات الثخصية \\
\hline & & & & r & التساوي & \\
\hline & & & & 1. & المجموع & \\
\hline \multirow[t]{4}{*}{$* \ldots}$. & r.Ar. & 00 & 0.0. & 1. & ال السالبة & \\
\hline & & $\cdots$ & $\cdots$ & . & الموجبة & العلاقات المهنية \\
\hline & & & & · & التساوي & \\
\hline & & & & 1. & المجموع & \\
\hline \multirow[t]{4}{*}{$* \ldots$} & r.Aro & 00 & 0.0 . & 1. & العالبة & \\
\hline & & $\cdots$ & $\cdots$ & . & الموجبة & أخلاقات العمل \\
\hline & & & & · & 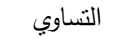 & \\
\hline & & & & 1. & المجموع & \\
\hline \multirow[t]{4}{*}{$* \ldots \wedge$} & $r .741$ & or.o & $0.9 \varepsilon$ & 9 & السالبة & \\
\hline & & 1.0 & 1.0. & 1 & الموجبة & الآداب والسلوكيات \\
\hline & & & & . & التساوي & \\
\hline & & & & 1. & المجموع & \\
\hline \multirow[t]{4}{*}{$* \ldots 11$} & $r .0 \leq 7$ & ri & ๕.0. & $\wedge$ & السالبة & المكان والزمان \\
\hline & & $\cdots$ & $\cdots$ & . & الموجبة & \\
\hline & & & & r & التساوي & \\
\hline & & & & 1. & المجموع & \\
\hline \multirow[t]{4}{*}{$* . . . V$} & $r .790$ & $\leqslant r .0$ & $0 . r 1$ & $\wedge$ & ال السالبة & المهارات المهنية \\
\hline & & r.o & r.o. & 1 & الموجبة & \\
\hline & & & & 1 & التساوي & \\
\hline & & & & 1. & المجموع & \\
\hline
\end{tabular}


الحيـاة عند الأشهاص ذوي الإعاقة الذهنية. ومـع (Kirkendall; دراسلة كيركندال دولك وسالادينو مـن Doueck \& Saladino, 2009) الهفاهيم الحياتية والاجتهاعية العامهة وتحقيق

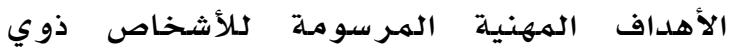
الإعاقة الذهنيـة.
إلى أهميـة إغناء وتنوع الههارات التي يتدرب عليها المعاق و عدم حصدرها في مهنـة دون غيرها

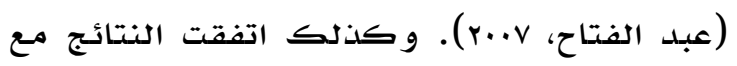
دراسة إنج (Inge, 1988) في أثر التدريب التتنافسي متعددد المهارات على السلوك التكيفي، الهشاركة الاجتماعية، الههارات الههنية وجودة

جدول ra

نتائج اختبار ويلكوكسون ودلالته الإحصائية للفروق بين متوسطي رتب درجات المجموعة الضابطة بين القياسين القبلي والبعدي على استبيان

\begin{tabular}{|c|c|c|c|c|c|c|}
\hline مستوى الدلالة & قيمة Z & مجموع الرتب & متوسط الرتب & 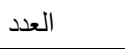 & الرتب & أبعاد استبيان بيركس \\
\hline \multirow[t]{4}{*}{.$M I V$} & $1 \ldots$ & Y.O. & r.o. & 1 & السالبة & العناية الشخصية \\
\hline & & V.o. & r.o. & r & الموجبة & \\
\hline & & & & 7 & 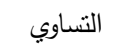 & \\
\hline & & & & $1 \cdot$ & المجموع & \\
\hline \multirow[t]{4}{*}{$.19 \varepsilon$} & $1 . r .$. & 1.0 & 1.0 & 1 & السالبة & السلامة المهنية \\
\hline & & ^.०. & r.Ar & r & الموجبة & \\
\hline & & & & 7 & 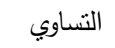 & \\
\hline & & & & $1 \cdot$ & المجموع & \\
\hline \multirow[t]{4}{*}{. . $\leqslant 97$} & $\because 7 \wedge$ & $0 .$. & $0 .$. & 1 & السالبة & \\
\hline & & $1 \cdots$ & T.O. & $\varepsilon$ & الموجبة & 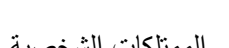 \\
\hline & & & & 0 & 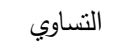 & 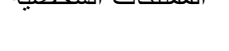 \\
\hline & & & & 1. & المجموع & \\
\hline \multirow[t]{4}{*}{.700} & $\cdot . \leqslant \leqslant V$ & $9 .$. & r... & r & السالبة & \\
\hline & & 7... & r... & r & الموجبة & ." \\
\hline & & & & 0 & 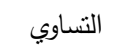 & العحتات المرة \\
\hline & & & & 1. & المجموع & \\
\hline \multirow[t]{4}{*}{$.19 \leq$} & $1 . r .$. & $\wedge .0$ & r.Ar & r & السالبة & \\
\hline & & 1.0 & 1.0 & 1 & الموجبة & أذلاقات المب \\
\hline & & & & 7 & التساوي & 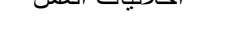 \\
\hline & & & & 1. & المجموع & \\
\hline \multirow[t]{4}{*}{. .700} & $\cdot . \leqslant \leqslant V$ & 7... & r... & r & السالبة & \\
\hline & & $9 .$. & r... & r & الموجبة & الآداب والسلوكيات \\
\hline & & & & 0 & التساوي & \\
\hline & & & & 1. & المجموع & \\
\hline \multirow[t]{4}{*}{$1 \ldots$} & $\cdots \cdots$ & $0 .$. & r.o. & r & السالبة & المكان والزمان \\
\hline & & $0 .$. & r.o. & r & الموجبة & \\
\hline & & & & 7 & التساوي & \\
\hline & & & & 1. & المجموع & \\
\hline \multirow[t]{4}{*}{.700} & $\cdot . \leqslant \leqslant V$ & $1 \ldots$ & $1 \ldots$ & 1 & السالبة & المهارات المهنية \\
\hline & & r... & r... & 1 & الموجبة & \\
\hline & & & & $\wedge$ & التساوي & \\
\hline & & & & 1. & المجموع & \\
\hline
\end{tabular}


الههنية و مشكلات مهنية اجتمهاعية، أكثر مـما هي مرتبطة بضعف في إنجاز مهام العمل الإنتاجية،

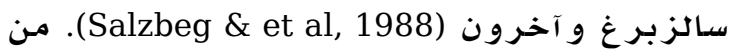
الهفيد هنا الإثـارة إلى ان بروان امـج التأهيل المهني

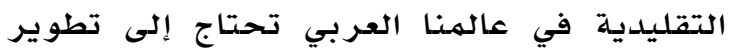

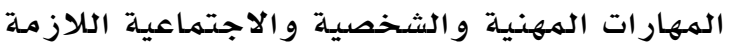

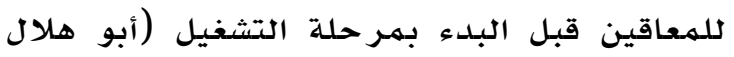

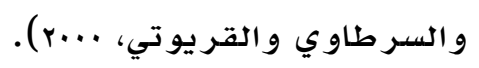

نتائج الفرضية الصفرية الثالثة: لا توجد فروق ذات دلادة إحصائية بين متوسطي رتب درجية دات المبه

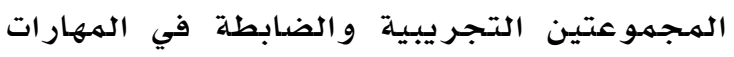

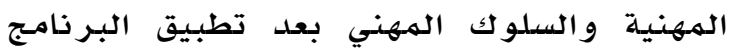

التتدر يبي.

يتضح من نتائج جدول (ع) وجود فروق ذات

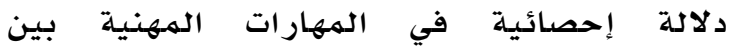
متوسطي رتب درجات المسجموعة التجريبية

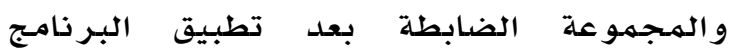

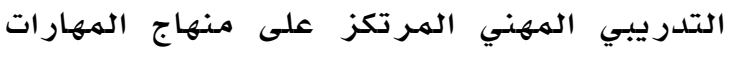

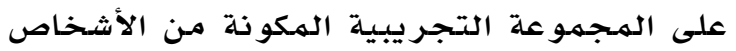
ذوي الإعاقة الذهنية البسيطة، حيث اتضح وجود الهود فروق بين الهجموعتين التجريبية والضـابطة في جميع الههارات الههنية الواردة في منهاج التأهيل المهني.

نتائج الفرضية الصفرية الثانية: لا توجد فروق ذات دلالة إحصائية بين متوسطي رتب درجات المجمو عة الضابطة بين القياسين القبلي والبعدي في المهارات المهنية و السلو ك المهني. يتضح من نتائج جدول (r) عدم وجود فرو فروق ذات دلالة إحصائية في مستوى المهارات المهنية بين

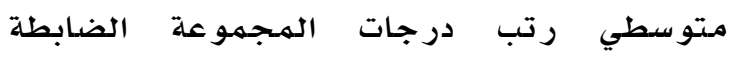
المكونة من الطلبـة ذوي الإعاقة الذهنية البسيطة

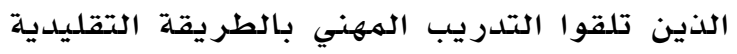

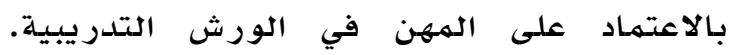

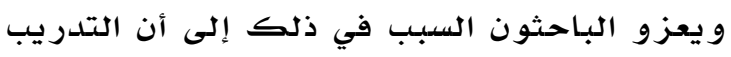

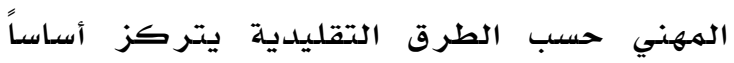

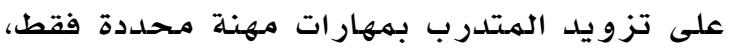

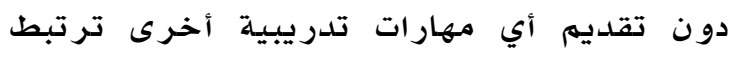
ببيئة العمل وقدرة المتدرب على التفاعل معها مهابها بعناصر ها المادية و البشرية، ووما يرتبط بها من

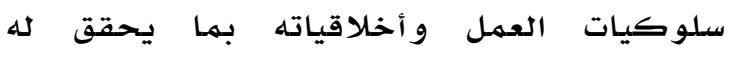

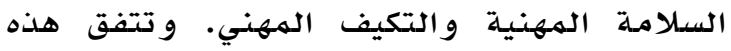

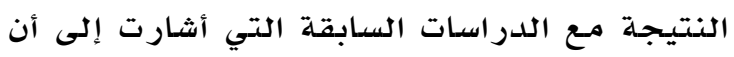

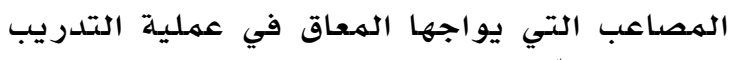

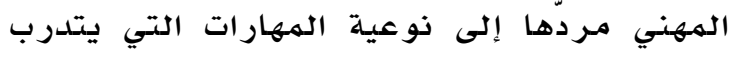

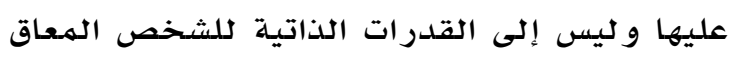

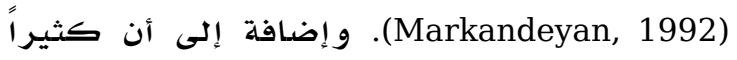
من المـوظفين مـن ذوي الإعاقة الذهنية قد فقدوا

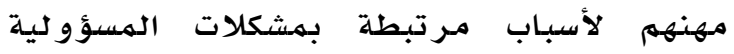
جدول ؛ نتائج اختبار مان ويتنني لوجود فروق بين المجموعتين التجريبية والضابطة بعد تطبيق البرنامج التتريبي

\begin{tabular}{|c|c|c|c|c|c|c|c|c|c|c|}
\hline \multirow[t]{2}{*}{ الدلالة الد } & \multirow[t]{2}{*}{ Z } & \multirow[t]{2}{*}{ W } & \multirow[t]{2}{*}{ U } & \multicolumn{3}{|c|}{ مجموع الرتب } & \multicolumn{2}{|l|}{ متوسط الرتب } & \multirow{2}{*}{ التثوسط } & \multirow[t]{2}{*}{ المجال } \\
\hline & & & & الضابطة & التجريبية & الضنابطة & التجريبية & الضابطة & & \\
\hline$* \ldots 1$ & r.rur & $7 \varepsilon$ & 9 & $7 \varepsilon$ & $1 \leq 7$ & T.ร. & $1 \varepsilon .7$ & r.^. & 0.9 & العناية الثخصية \\
\hline$* \ldots$ & ז.7וт & $0 \wedge$ & r & $0 \wedge$ & lor & $0 . \Lambda$. & 10.r. & r.^. & $\mathrm{V.l}$. & السلامة المهنية \\
\hline$* \ldots 1$ & r. $\leq \varepsilon \leq 1$ & 7) & 7 & 71 & $1 \leq 9$ & 7.1 & $1 \leq .9$. & $\varepsilon . \mu$. & १. . & الممنلكات \\
\hline & & & & & & & & & & الشخصية \\
\hline$* \ldots 1$ & & 7) & 7 & 71 & $1 \leq 9$ & 7.1 & $1 \leq .9$ & r.q. & 7.9. & العلاقات المهنية \\
\hline$* \ldots$ & r.vir & ov & r & ov & lor & $0 . v$. & 10.r. & r.v. & ๆ.^. & أخلاقيات العمل \\
\hline$* \ldots$ & 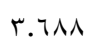 & $0 \wedge$ & 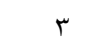 & Oᄉ & lor & $0 . \wedge$. & $10 . r$. & $\varepsilon .0$ & V.r. & الآداب والسلوكيات \\
\hline$* \ldots 1$ & r.YAE & Tr & v & Tr & $1 \leqslant \Lambda$ & T.r. & $1 \leq . \wedge$ & r.v. & 7.9. & المكان والزمان \\
\hline$* \ldots q$ & r.717 & VT.O & $1 V .0$ & VY.O & IrV.o & V.YO & Ir.vo & $\varepsilon .0$. & T.Y. & المهارات المهنية \\
\hline
\end{tabular}


حياتهم العملية في بيئة العمل، وليس فقط النجاح في أداء الههارات الههينية

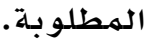

تقديه جزء من الههارات التدريبية

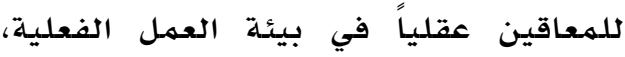
وذلك بهدف كسر الحواجز النفسية نحو العهل و سـرعة الاستقر ار و التكيف الههني. تقديم الخدمات النفسية و والاجتماعية للمعاقين المتدربين في مرحلة التأهيل الههني لمساعدتهم على التكيف مـع بيئة العهل و متطلبـاتها.

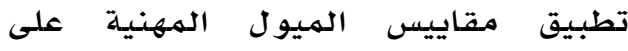
الأشخاص ذوي الإعاقة الذهنية المتدربئ في أقسام التأهيل الههني لضهمان نجاح

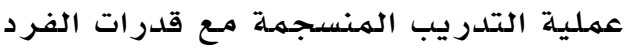
و احتياجاته.

مواكبة التغيرات الحاصلة في بيئة العمل و التعرف على متطلبـاتها الجسدية و العقلية بهاف إجراء التعديلات على الههارات

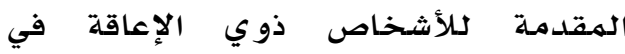
مـرحلة التأهيل المهني. متابعة الأشخاص ذ ذوي الإعاقة بعد

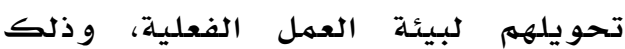

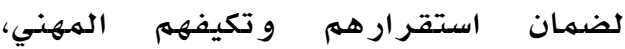
وتخطي العقبات التي قد تظهر في بدايات

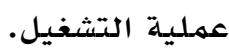

\section{المر اجع}

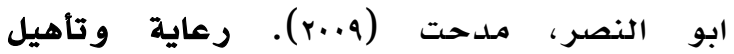
المعاقين. القاهرة: دار الروابط العالمية للنشر و التوزيع.

أبـو هـلال، مــاهر ؛ والســر طاوي، عبـــ العزيـز ؛

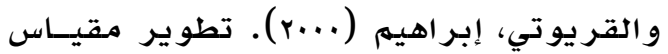

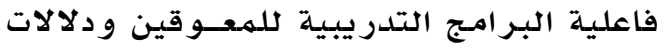
الصــــق و الثبــات: در اســة عامليــة. دراســات نفسـية. تصــدر عـن رابطـــة الأخصـائيين

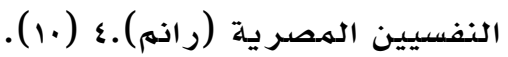

و يعزو الباحثون السبب في ذلك إلى أن برنامـج

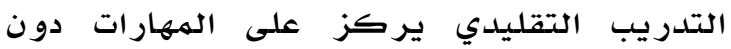
تزويد المتدرب بكيفية الحفاظ على أمنه وسلامتته من المخاطر الموجودة في بيئة العمل، و كذلك كيفية الحفاظ على الأدوات و التواصل

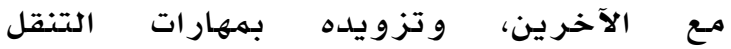

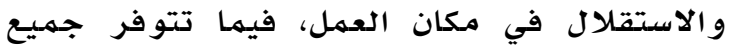
هذه الههارات التدريبية في منهاج التأهيل الههني

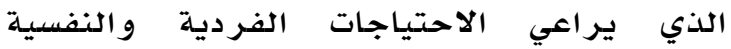

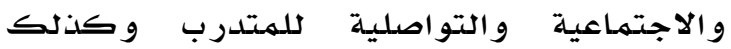
تمكينه من مهارات التكيف في بيئة العهل و التطور والنهمو فيها. وكما تتفق هذه النتيجة مـع دراسـة إنج (Inge, 1988) في و وجود مستوى ولهو

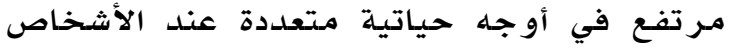

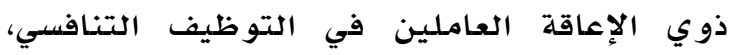
حيث يتلقون أشكالاً متعددة من التهن التدريب تتمثل في السلوك التكيفي و المشاركة الاجتماعية،

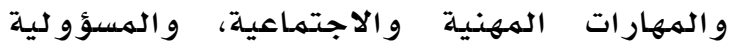

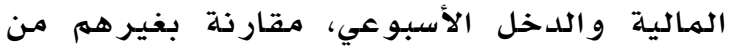

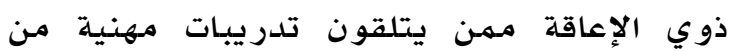
خلال ورث العمل التقليدية، وتتفق مـع دراسـة أجرى موري ودورين (Murray \& Doren, 2013)

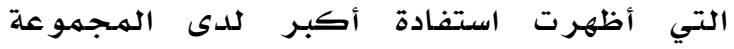

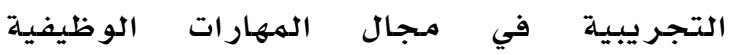
والاجتماعيلة.

التوصيات

بناء على نتائج الدراسـة، قدم البـاحثون التوصيات

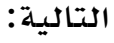

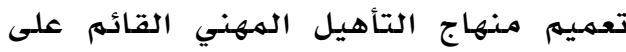

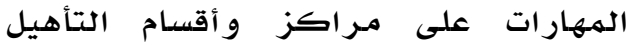
المهني للمعاقين عقلياً في دولة الإمارات، وذلك بغرض الاستفادة منـه في تطوير

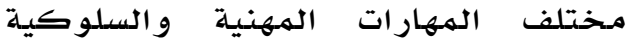
و الاجتماعية اللازمة في بيئة العمل. التوسع في برامج التأهيل الههني الهقدمة

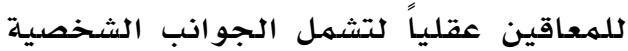
والاجتماعية التي تمكنهم من مهارسة 


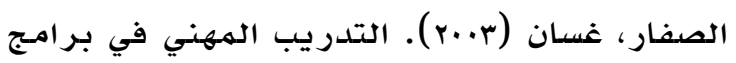

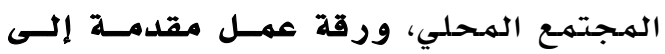

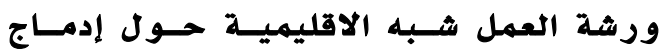

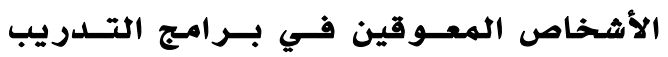
المهني، عمان.

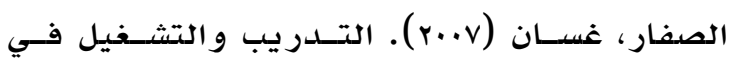

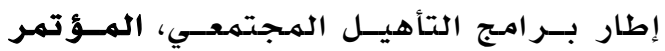
العربية الإقليمي حول تدريب وتشغيل ذوي إلهاري الاحتياجات الخاصة، العين: Or-Y مـارس.

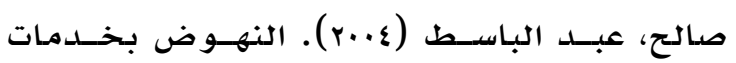

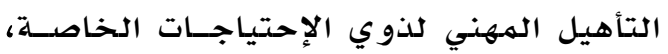

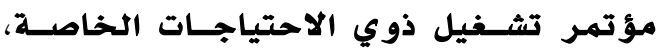
الشار قة، آr-צr فبر اير .

عبدات، روحي (11) (ب). تأهيل وتشغيل الأشخاص الاص

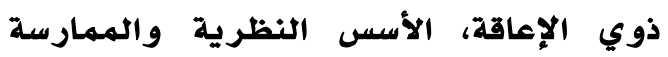

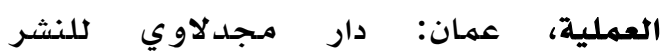
و التوزيع.

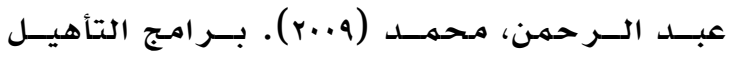

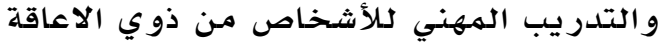
الذهنية، ورقة مقدمة إلى الندوة الاجتماعية

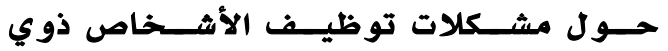
الإعاقة في دول مجلس التعـاون الخليجسي، دبي: •.ا-11 يو نيو.

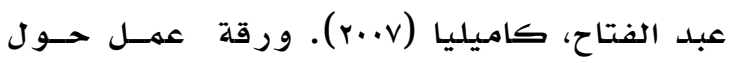

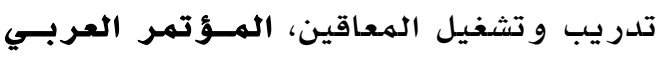

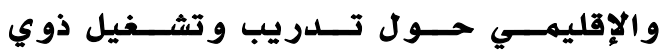

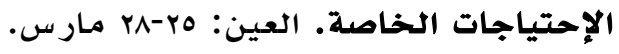

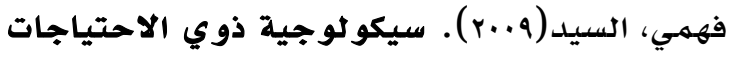

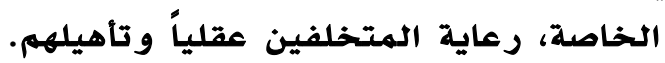
القاهرة: دار الجامعة الجديدة.

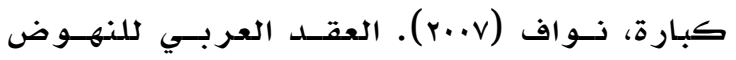

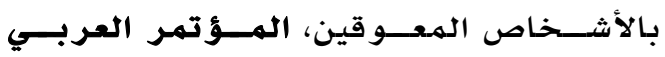

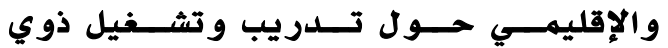

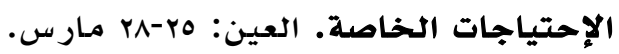

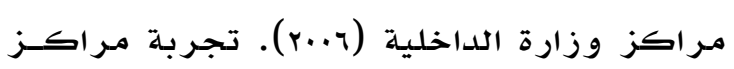

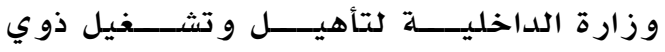
الاحتياجات الخاصد، الندوة القوميــة حــول

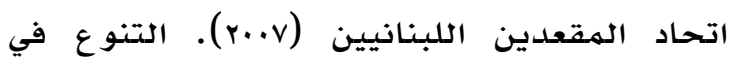

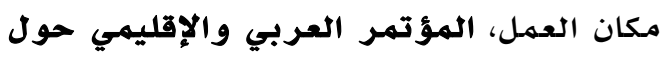
تدريب وتشغيل ذوي الاحتياجات الخاصة.

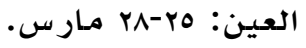

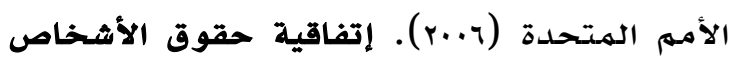

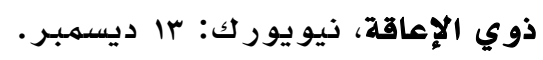
الخطيب، جهـال (1991). تقـوم بــرامج التأهيـل المهني للمعوقين من وجهة نظر المنتفعين

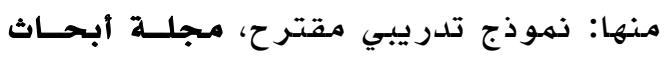
اليرمو ك. العدد (v).

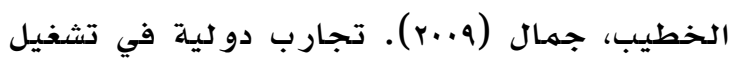

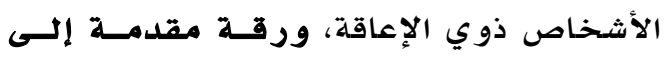

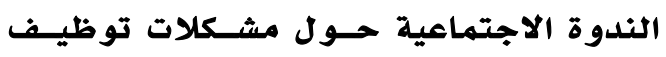

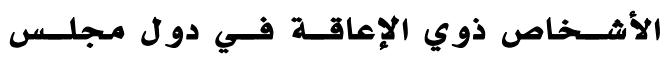
التعاون الخليجي، دبي: .ا-lا يونيو.

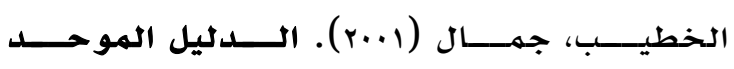

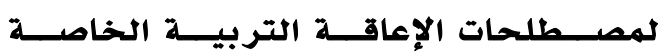

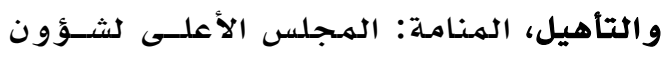

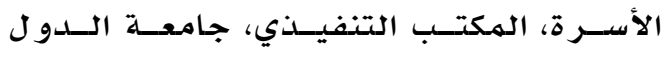
العر بية.

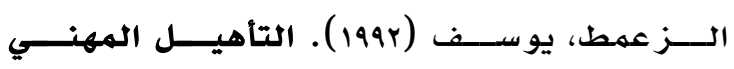

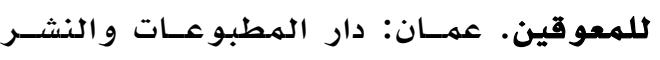
الهـجمـع الكنسي.

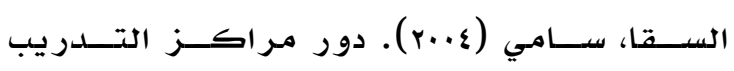

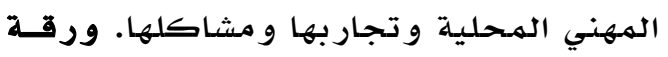

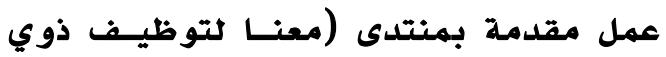

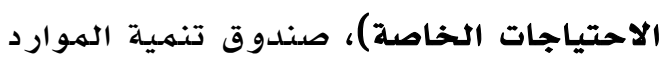

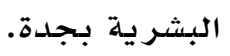

الشمري، مشوح (1994). تقـويم فاعليــة بـرامج

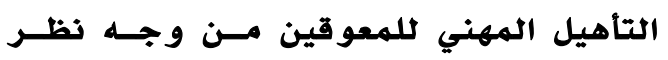

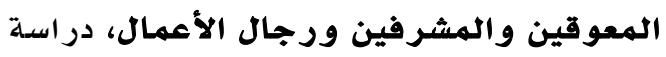

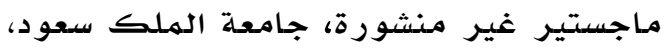
كلية الآداب، المملكة العربية السعودية. الشواهين، علي (1919). تقويم خــدمات التأهيـل

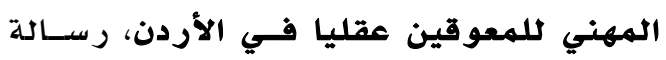

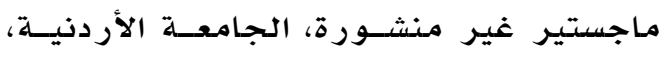
كلية التربية، المملكة الأردنية الهاشمية. 
American Association on Mental Retardation. (2002). Mental Retardation: Definition, Classification, and Systems of Supports, 10th Edition. Washington, DC: American Association on Mental Retardation

Bellamy, G. T., Rhodes, L. E., Bourbeau, P. E. \& Mank, D. M. (1986). Mental retardation service in sheltered workshops and day activity programs: consumer benefits and policy alternatives. In F.R. Rusch (Ed.), Competitive employment issues and strategies (pp. 257-272). Baltimore: Brookes.

Fleming, A., Del, V., Kim, M., \& Leahy, M. (2013). Best Practice Models of Effective Vocational Rehabilitation Service Delivery in the Public Rehabilitation Program: A Review and Synthesis of the Empirical Literature. Rehabilitation Counseling Bulletin, 56 (3) 146-159.

Inge, K. J., Banks, P. D., Wheman, P. Hill, J. W. \& Sharer, M. S. (1988). Quality of life for individuals who are labeled mentally retarded. Evaluating competitive employment versus sheltered workshop employment. Education and Training in Mental Retardation. 23, 97-104.

Kirkendall, A., Doueck, H., \& Saladino, A. (2009). Transitional Services for Youth with Developmental Disabilities: Living in College Dorms. Research on Social Work Practice, 19 (4) 434-445.

Kniel, A. (1995). The present situation of former pupils from schools for the mentally retarded: Experiences from four countries in western and central Africa. International Journal of Rehabilitation Research, 18 (4), 357-361.

Markandeyan S. (1992). Vocational Training and Employment for the Handicapped, Seminar Paper Karalla Federation of the Blind, Trivandrum.

Murray, C. \& Doren, B. (2013). The Effects of Working at Gaining Employment Skills on the Social and Vocational Skills of Adolescents with Disabilities: A SchoolBased Intervention. Rehabilitation Counseling Bulletin.56 (2) 96-107.

Salzberg, C. L., Lignugaris/Kraft, B., \& McCuller, G. L. (1988). Reasons for job loss: A review of employment termination studies of mentally retarded workers.

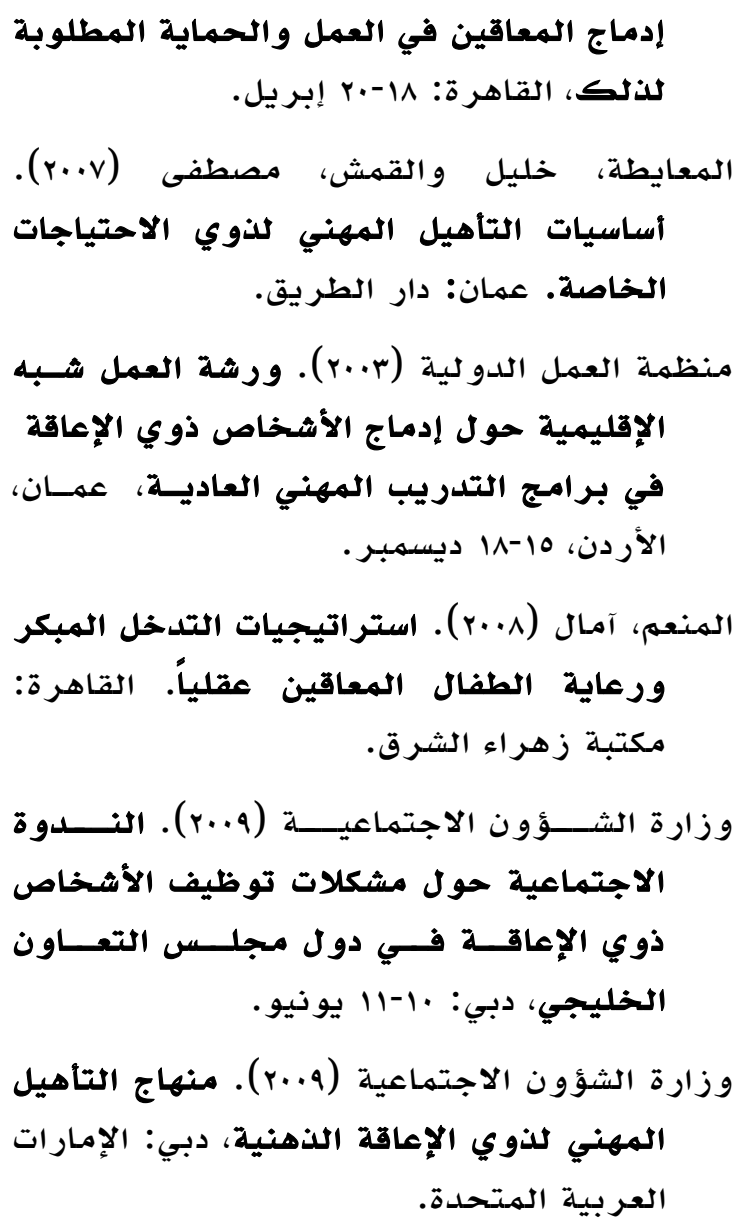


Research in Developmental Disabilities, 9, 153169.

Schalock RL, Borthwick-Duffy SA, Bradley M et al. (2010). Intellectual disability: definition, classification, and systems of supports, 11th ed. Washington: American Association on Intellectual and Developmental Disabilities. 